Virginia Commonwealth University VCU Scholars Compass

2017

\title{
Multiple blood-brain barrier transport mechanisms limit bumetanide accumulation, and therapeutic potential, in the mammalian brain
}

Kerstin Römermann

University of Hannover

Maren Fedrowitz

University of Hannover

Philip Hampel

University of Hannover, Center for Systems Neuroscience

See next page for additional authors

Follow this and additional works at: http://scholarscompass.vcu.edu/phtx_pubs

Part of the Medical Pharmacology Commons

(C) 2017 Elsevier Ltd. All rights reserved.

\section{Downloaded from}

http://scholarscompass.vcu.edu/phtx_pubs/47

This Article is brought to you for free and open access by the Dept. of Pharmacology and Toxicology at VCU Scholars Compass. It has been accepted for inclusion in Pharmacology and Toxicology Publications by an authorized administrator of VCU Scholars Compass. For more information, please contact libcompass@vcu.edu. 
Authors

Kerstin Römermann, Maren Fedrowitz, Philip Hampel, Edith Kaczmarek, Kathrin Töllner, Thomas Erker, Douglas H. Sweet, and Wolfgang Löscher 


\title{
Multiple blood-brain barrier transport mechanisms limit bumetanide accumulation, and therapeutic potential, in the mammalian brain
}

\author{
Kerstin Römermann ${ }^{\text {a }}$, Maren Fedrowitz ${ }^{\text {a, }}$, Philip Hampel ${ }^{\text {a, b }}$, Edith Kaczmarek ${ }^{\text {a }}$, \\ Kathrin Töllner ${ }^{\mathrm{a}}$, Thomas Erker ${ }^{\mathrm{c}}$, Douglas H. Sweet ${ }^{\mathrm{d}}$, Wolfgang Löscher ${ }^{\mathrm{a}, \mathrm{b},{ }^{*}}$ \\ a Department of Pharmacology, Toxicology, and Pharmacy, University of Veterinary Medicine Hannover, Germany \\ ${ }^{\mathrm{b}}$ Center for Systems Neuroscience, Hannover, Germany \\ ${ }^{\mathrm{c}}$ Department of Medicinal Chemistry, University of Vienna, Vienna, Austria \\ d Department of Pharmaceutics, Virginia Commonwealth University, Richmond, VA, USA
}

\section{A R T I C L E I N F O}

\section{Article history:}

Received 16 November 2016

Received in revised form

31 January 2017

Accepted 7 February 2017

Available online 10 February 2017

\section{Keywords:}

Organic anion transporters

Probenecid

Bumetanide derivatives

NKCC1

\begin{abstract}
A B S T R A C T
There is accumulating evidence that bumetanide, which has been used over decades as a potent loop diuretic, also exerts effects on brain disorders, including autism, neonatal seizures, and epilepsy, which are not related to its effects on the kidney but rather mediated by inhibition of the neuronal $\mathrm{Na}-\mathrm{K}-\mathrm{Cl}$ cotransporter isoform NKCC1. However, following systemic administration, brain levels of bumetanide are typically below those needed to inhibit NKCC1, which critically limits its clinical use for treating brain disorders. Recently, active efflux transport at the blood-brain barrier (BBB) has been suggested as a process involved in the low brain:plasma ratio of bumetanide, but it is presently not clear which transporters are involved. Understanding the processes explaining the poor brain penetration of bumetanide is needed for developing strategies to improve the brain delivery of this drug. In the present study, we administered probenecid and more selective inhibitors of active transport carriers at the BBB directly into the brain of mice to minimize the contribution of peripheral effects on the brain penetration of bumetanide. Furthermore, in vitro experiments with mouse organic anion transporter 3 (Oat3)overexpressing Chinese hamster ovary cells were performed to study the interaction of bumetanide, bumetanide derivatives, and several known inhibitors of Oats on Oat3-mediated transport. The in vivo experiments demonstrated that the uptake and efflux of bumetanide at the BBB is much more complex than previously thought. It seems that both restricted passive diffusion and active efflux transport, mediated by Oat3 but also organic anion-transporting polypeptide (Oatp) Oatp1a4 and multidrug resistance protein 4 explain the extremely low brain concentrations that are achieved after systemic administration of bumetanide, limiting the use of this drug for targeting abnormal expression of neuronal NKCC1 in brain diseases.
\end{abstract}

(๑) 2017 Elsevier Ltd. All rights reserved.
Abbreviations: BBB, blood-brain barrier; BCEC, brain capillary endothelial cell; BCRP, breast cancer resistance protein; BUM5, $\mathrm{N}, \mathrm{N}$-dimethylaminoethylester of bumetanide; BUM13, 5-(anilinomethyl)-3-(butylamino)-2-phenoxy-benzenesulfonamide; CHO, Chinese hamster ovary; CSF, cerebrospinal fluid; HPLC, high performance liquid chromatography; i.c.v., intracerebroventricular; MCT, monocarboxylic acid transporter; MRP, multidrug resistance protein; NKCC, Na-K-Cl cotransporter; Oat, organic anion transporter; Oatp, organic anion-transporting polypeptide; $\mathrm{PAH}$, para-aminohippuric acid; P-gp, P-glycoprotein; SLC, solute carrier.

* Corresponding author. Department of Pharmacology, Toxicology and Pharmacy, University of Veterinary Medicine, Bünteweg 17, D-30559 Hannover, Germany.

E-mail address: wolfgang.loescher@tiho-hannover.de (W. Löscher).

1 Present address: Merck Animal Health, Drug Discovery \& MRL Liaison, Madison, NJ 07940, USA.

\section{Introduction}

The blood-brain barrier (BBB), which functions as a protective barrier to shield the brain from neurotoxic substances, consists of a physical barrier formed primarily by the endothelial tight junctions and a transport barrier resulting from efflux transporters expressed in the endothelial membrane (Abbott et al., 2010). Efflux transport at the BBB limits the brain tissue exposure to a variety of therapeutic agents, including compounds that are highly lipophilic and would easily permeate through the BBB in the absence of efflux transport (Löscher and Potschka, 2005a). Drug efflux at the BBB is thought to be mainly mediated by $A B C$ transporters such as $\mathrm{P}$ glycoprotein (P-gp; $A B C B 1$ ), breast cancer resistance protein (BCRP; 
$A B C G 2$ ) and members of the multidrug resistance protein (MRP; $A B C C$ ) family expressed at the luminal (apical) site of brain capillary endothelial cells (BCECs), but members of the multispecific organic anion transporter (OAT; SLC22A) and organic anion-transporting polypeptide (OATP; SLCO) families may also contribute to drug efflux (Sun et al., 2003; Ohtsuki, 2004; Kusuhara and Sugiyama, 2005; Löscher and Potschka, 2005b; Urquhart and Kim, 2009). In rodents, particularly Oat3 (Slc22a8) and Oatp1a4 (Slco1a4; previously termed Oatp2) are expressed at the BBB and are thought to be involved in drug transport (Ohtsuki, 2004; Kusuhara and Sugiyama, 2005; Löscher and Potschka, 2005b; Urquhart and Kim, 2009). Oat3 is predominantly expressed at the abluminal (basolateral) membrane of BCECs, takes up its substrates from brain interstitial fluid into BCECs and so plays a major role in the brain-to-blood efflux transport system of a broad range of compounds (Ohtsuki, 2004; Kusuhara and Sugiyama, 2005; VanWert et al., 2010; Burckhardt, 2012). Oatp1a4 is expressed in both the luminal and the abluminal membranes of brain capillary endothelial cells and can mediate the transcellular transport of amphipathic organic anions across the BBB in both the blood-to-brain and brain-to-blood directions (Ose et al., 2010). In humans, OAT3 (SLC22A8) is also involved in drug efflux at the BBB, whereas OATP1A2 (SLCO1A2), the closest counterpart of rodent Oatp1a4, seems to mainly mediate drug uptake into the brain (Urquhart and Kim, 2009).

The loop diuretic bumetanide is long known to be a substrate of OAT3/Oat3 in the kidney, which, together with other OATs, mediates its uptake into renal tissue and allows bumetanide to reach its target Na-K-Cl cotransporter NKCC (Burckhardt, 2012). Recently, Donovan et al. $(2015,2016)$ suggested that OAT3/Oat3 also mediates the efflux of bumetanide at the BBB, thus significantly contributing to the low brain levels of bumetanide obtained after systemic administration (Löscher et al., 2013). Apart from its diuretic effect, which is mediated by the NKCC isoform NKCC2, bumetanide blocks NKCC1 and is the only available selective inhibitor of this NKCC isoform (Löscher et al., 2013). Overexpression of NKCC1 in neurons is thought to be involved in several brain diseases, including neonatal seizures and temporal lobe epilepsy, the most common type of epilepsy in adult patients (Kahle et al., 2008; Blaesse et al., 2009; Ben-Ari et al., 2012; Löscher et al., 2013; Kaila et al., 2014). This attracted substantial interest in using bumetanide as a rational therapy for treating such brain diseases. However, the poor brain penetration of bumetanide limits its use and is a likely explanation for the failure of clinical trials (Löscher et al., 2013; Puskarjov et al., 2014; Pressler et al., 2015). Donovan et al. $(2015,2016)$ proposed to increase brain levels of bumetanide by inhibiting its brain efflux. However, systemic administration of the Oat inhibitor probenecid in rats increased bumetanide levels in both plasma and brain without any alteration in brain:plasma ratio (Donovan et al., 2015), indicating that the increased brain levels of bumetanide were a consequence of Oat inhibition in the kidney, resulting in reduced clearance of bumetanide. Similar data were reported by our group in mice (Töllner et al., 2015), so that it is presently not clear whether bumetanide is subject to active efflux transport at the BBB and, if so, which transporters are involved. Indeed, the low brain concentrations reached after systemic administration of bumetanide (brain:plasma ratio $\sim 0.01-0.02$ in adult rodents) could also be a consequence of its high ionization rate $(>99 \%)$ at physiological $\mathrm{pH}$ and its high plasma protein binding ( $>95 \%$ ), which restrict brain entry of bumetanide by passive diffusion (Löscher et al., 2013; Puskarjov et al., 2014).

In the present study, we administered probenecid and more selective inhibitors of active transport carriers at the BBB directly into the brain of mice to minimize the contribution of peripheral effects on the brain penetration of bumetanide. Furthermore, in vitro experiments with mouse Oat3-overexpressing Chinese hamster ovary $(\mathrm{CHO})$ cells were performed to study the interaction of bumetanide, bumetanide derivatives, and several known Oat inhibitors on Oat3-mediated transport as a basis for the in vivo experiments.

\section{Materials and methods}

\subsection{Animals}

Outbred NMRI mice were obtained from Charles River (Sulzfeld, Germany). Body weight at arrival was $20-25 \mathrm{~g}$. As in our previous experiments with bumetanide (Töllner et al., 2014, 2015; Töpfer et al., 2014), female animals were used, because they usually eliminate drugs more slowly than males and can be kept in groups more easily. Animals were housed under controlled conditions (ambient temperature $22-24{ }^{\circ} \mathrm{C}$, humidity $30-50 \%$, lights on from 6:00 a.m. to 6:00 p.m.) and adapted to the laboratories for at least one week before being used in the experiments. Food (Altromin 1324 standard diet) and water were freely available.

Experiments were performed according to the EU council directive 2010/63/EU and the German Law on Animal Protection ("Tierschutzgesetz"). Ethical approval for the study was granted by an ethical committee (according to $\S 15$ of the Tierschutzgesetz) and the government agency (Lower Saxony State Office for Consumer Protection and Food Safety; LAVES) responsible for approval of animal experiments in Lower Saxony (reference number for this project: 15/1825). All efforts were made to minimize both the suffering and the number of animals.

\subsection{Drugs and chemicals}

If not stated otherwise, drugs or chemicals (cf., Fig. 1) were purchased from Sigma-Aldrich (Munich, Germany) and were of analytical grade. For the in vivo experiments, bumetanide was dissolved in an aqueous $10 \%$ solution of hydroxypropyl- $\beta$-cyclodextrin (HP $\beta C D$; Kleptoses, Roquette-Pharma, Frankfurt, Germany) as described previously (Töllner et al., 2014, 2015; Töpfer et al., 2014). For intracerebroventricular (i.c.v.) injection, probenecid, para-aminohippuric acid (PAH) and sodium taurocholic acid were dissolved (PAH by means of $1 \mathrm{mM} \mathrm{NaOH}$ ) in artificial cerebrospinal fluid (CSF; pH adjusted to 7.4 with $\mathrm{HCl}$ ). Elacridar hydrochloride was provided by GlaxoSmithKline (Research Triangle Park, NC) and dissolved in CSF containing $0.15 \%$ Cremophor EL ${ }^{\circledR}$ (Caelo; Hilden, Germany). In most in vivo experiments, methylene blue was included in the artificial CSF as described below. For in vitro transport experiments bumetanide was used as commercial solution $(0.5 \mathrm{mg} / \mathrm{ml})$ of the sodium salt of bumetanide (Burinex), which was kindly provided by Leo Pharma (Ballerup, Denmark) and diluted in Opti-MEM ${ }^{\mathbb{R}}$ (Gibco ${ }^{\mathbb{R}} /$ Life Technologies Corporation). The bumetanide derivatives Bum5 (Töllner et al., 2014) and Bum13 (Lykke et al., 2015) were synthesized by one of us (T.E.) and dissolved in dimethyl sulfoxide for in vitro experiments. Fluorescein (Invitrogen ${ }^{\mathrm{TM}} /$ Life Technologies Corporation; Darmstadt, Germany) was dissolved in phosphate buffered saline. Probenecid (by means of $1 \mathrm{mM} \mathrm{NaOH}$ ) and cimetidine were dissolved in distilled water, PAH in Opti-MEM ${ }^{\circledR}$ medium (Gibco ${ }^{\circledR} /$ Life Technologies Corporation, Darmstadt, Germany; pH adjusted to 7.4 with $\mathrm{HCl}$ ), and digoxin in dimethyl sulfoxide.

\subsection{Pharmacokinetic experiments with probenecid in mice}

Since previous experiments on potential BBB transport of bumetanide have been performed with systemic administration of probenecid, using $50 \mathrm{mg} / \mathrm{kg}$ in mice (Töllner et al., 2015) and rats (Donovan et al., 2015), we examined whether this systemic dose of 
<smiles>CCCCNc1cc(C(=O)O)cc(S(N)(=O)=O)c1Oc1ccccc1</smiles>

Bumetanide<smiles>Nc1ccc(C(=O)NCC(=O)O)cc1</smiles><smiles>CCCCNc1cc(C(=O)OCCN(C)C)cc(S(N)(=O)=O)c1Oc1ccccc1</smiles>

BUM5

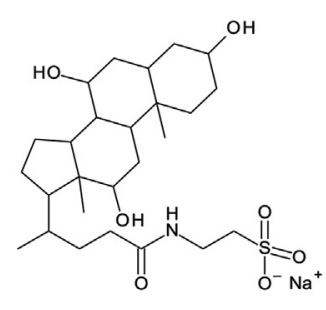<smiles>CCCCNc1cc(CNc2ccccc2)cc(S(N)(=O)=O)c1Oc1ccccc1</smiles>

BUM13

Methylene blue
para-Aminohippuric acid<smiles>COc1cc2c(cc1OC)CN(CCc1ccc(NC(=O)c3cccc4c(=O)c5cccc(OC)c5[nH]c34)cc1)CC2</smiles>

Elacridar
Sodium Taurocholate

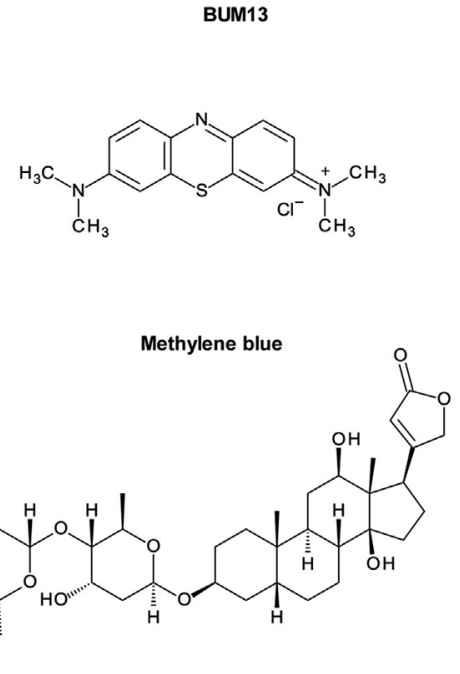

Digoxin<smiles>CCCN(CCC)S(=O)(=O)c1ccc(C(=O)O)cc1</smiles>

Probenecid<smiles>O=C(O)c1ccccc1-c1c2ccc(=O)cc-2oc2cc(O)ccc12</smiles>

Fluorescein

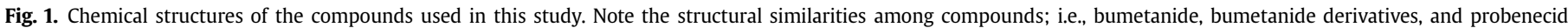
contain a sulfonamide group, and both methylene blue and fluorescein are tricyclic structures.

probenecid results in brain concentrations known to inhibit Oats. Probenecid, $50 \mathrm{mg} / \mathrm{kg}$, was administered i.p. and groups of mice were killed either after 45, 60 or $75 \mathrm{~min}$ for determination of probenecid in plasma and brain. Probenecid (Sigma-Aldrich; Munich, Germany) was dissolved in saline (by means of dilute $\mathrm{NaOH}$ ) and injected with an injection volume of $10 \mathrm{ml} / \mathrm{kg}$.

In a subsequent series of experiments, we administered different doses of probenecid $(25,50$ or $150 \mu \mathrm{g})$ into the right lateral ventricle of mice under anesthesia with isoflurane. These i.c.v. doses of probenecid would result in molar brain concentrations of $0.175,0.35$ and $1.05 \mathrm{mM}$ probenecid, assuming homogeneous brain distribution and an average mouse brain weight of $0.5 \mathrm{~g}$. For comparison, an intracerebral concentration of $2.2 \mathrm{mM}$ probenecid has been reported to completely inhibit brain efflux of the Oat3 dehydroepiandrosterone sulfate substrate in mice (Miyajima et al., 2011). However, such calculation ignores that probenecid diffusion into brain tissue after i.c.v. injection will not be homogeneous throughout the brain and that the drug will be rapidly eliminated, so that this calculation overestimates the brain concentrations of probenecid reached after i.c.v. injection (see Results). For i.c.v. injection, probenecid was injected in a volume of $10 \mu$, using the technique described by Kim et al. (1998) and Laursen and Belknap (1986). The probenecid solution contained $0.16 \%$ methylene blue ((3,7-bis(dimethylamino)-phenothiazin-5ium chloride; Fig. 1) to verify correct injection in the ventricle after killing the animals either 15 or 45 min following i.c.v. injection. Only animals with correct injection were used for final data analyses. Probenecid was determined in plasma and brain (separately in each hemisphere) as described below.

\subsection{Effects of i.c.v. probenecid on bumetanide brain levels in mice}

In a first series of experiments, different doses of probenecid $(25,50$ or $150 \mu \mathrm{g})$ were administered i.c.v. (into the right lateral ventricle), followed 15 min later by i.v. administration of bumetanide. Controls received i.c.v. injections of vehicle (artificial CSF) with methylene blue (which was also included in the probenecid solutions). Anesthesia with isoflurane was not maintained after i.c.v. injection of probenecid, so that mice were conscious at time of bumetanide administration and blood and brain sampling. Bumetanide was injected at a dose of $10 \mathrm{mg} / \mathrm{kg}$ i.v. with an injection volume of $10 \mathrm{ml} / \mathrm{kg}$ in groups of mice. Mice were killed $30 \mathrm{~min}$ after bumetanide for bumetanide analysis in plasma and brain. In a second series of experiments, only the highest dose of probenecid $(150 \mu \mathrm{g})$ was injected i.c.v. and bumetanide $(10 \mathrm{mg} / \mathrm{kg}$ i.v. $)$ was immediately injected after probenecid (within 1-2 min) or $30 \mathrm{~min}$ after probenecid and mice were killed 15 min after bumetanide for bumetanide analysis in plasma and brain.

\subsection{Effects of i.c.v. para-aminohippuric acid (PAH) on bumetanide brain levels in mice}

Probenecid is not a selective inhibitor of Oat3 but also inhibits other Oats, several Oatps and MRPs (see Discussion and Table 1). We therefore included another widely used Oat inhibitor, PAH (Fig. 1), which has been shown to be transported by Oat3 but not Oatp1a4 at the mouse BBB and inhibits Oat3 at high concentrations (Kikuchi et al., 2003; Miyajima et al., 2011; see also Table 1). In a first experiment, two different doses of PAH (50 and $100 \mu \mathrm{g} / 10 \mu \mathrm{l}$ ) were injected into the right lateral ventricle immediately followed (within $1-2 \mathrm{~min}$ ) by i.v. administration of bumetanide $(10 \mathrm{mg} / \mathrm{kg}$ 
Table 1

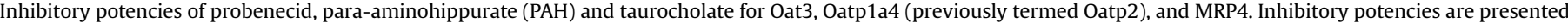

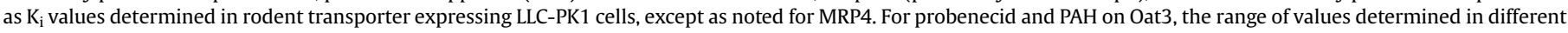
studies is shown. Bumetanide was not used in any of these studies.

\begin{tabular}{|c|c|c|c|c|}
\hline \multirow[t]{2}{*}{ Transport inhibitor } & \multicolumn{3}{|l|}{$\mathrm{K}_{\mathrm{i}}(\mu \mathrm{M})$} & \multirow[t]{2}{*}{ Reference } \\
\hline & Oat3 & Oatp1a4 (Oatp2) & $\mathrm{MRP}^{\mathrm{a}}$ & \\
\hline Probenecid & $1-20$ & 73 & $<100 \mu \mathrm{M}$ & Sugiyama et al., 2001; Van Aubel et al., 2002; VanWert et al., 2010 \\
\hline $\mathrm{PAH}$ & $300-1350$ & $>5000$ & $?\left(\mathrm{~K}_{\mathrm{m}} 160 \mu \mathrm{M}\right)$ & Sugiyama et al., 2001; Smeets et al., 2004; VanWert et al., 2010 \\
\hline Taurocholate & 790 & 39.4 & $?$ & Sugiyama et al., 2001; VanWert et al., 2010 \\
\hline
\end{tabular}

${ }^{\text {a }}$ Human MRP4-expressing Sf9 vesicles.

i.v.). Assuming homogeneous brain distribution and an average mouse brain weight of $0.5 \mathrm{~g}$, these i.c.v. doses of PAH would result in molar brain concentrations of 0.51 and $1.03 \mathrm{mM}$, respectively. Mice were killed $15 \mathrm{~min}$ after bumetanide for bumetanide analysis in plasma and brain. In a second experiment, higher doses of $\mathrm{PAH}$ $(250,500$, and $1000 \mu \mathrm{g} / 10 \mu \mathrm{l})$ were injected i.c.v. Because convulsions were observed at these doses (see Results), the experiment with $250 \mu \mathrm{g}$ was repeated in mice in which anesthesia with isoflurane was maintained over the duration of the experiment. As in the experiments with probenecid, methylene blue was included in the PAH solution in the majority of experiments. Controls received i.c.v. injections of artificial CSF with methylene blue.

\subsection{Effects of i.c.v. taurocholate on bumetanide brain levels in mice}

Additional experiments were performed with taurocholate (Fig. 1) to determine whether Oatp1a4, which is not inhibited by $\mathrm{PAH}$, is involved in brain efflux of bumetanide. As shown in Table 1, taurocholate is 20 times more potent to inhibit Oatp1a than Oat3. Taurocholate (dissolved as its sodium salt) was injected at a dose of $108 \mu \mathrm{g} / 10 \mu \mathrm{l}$ in two experiments; in one experiment, isoflurane was only used for i.c.v. injection, whereas in the other experiments anesthesia was maintained for the whole duration of the experiment (see Results). Assuming homogeneous brain distribution and an average mouse brain weight of $0.5 \mathrm{~g}$, this i.c.v. dose of taurocholate would result in a molar brain concentration of $0.4 \mathrm{mM}$. As in the experiments with probenecid and $\mathrm{PAH}$, methylene blue was included in the taurocholate solution in the majority of experiments. Controls received i.c.v. injections of artificial CSF with methylene blue.

\subsection{Effects of i.c.v. elacridar and methylene blue on bumetanide brain levels in mice}

We previously observed a moderate but statistically significant transport of bumetanide in Bcrp-overexpressing pig kidney LLCPK1 cells (Töllner et al., 2015), so that we determined whether inhibition of brain Bcrp increases bumetanide levels in the brain. For this purpose we used elacridar (Fig. 1), which potently inhibits P-gp and Bcrp in vitro and in vivo (Matsson et al., 2009; Bankstahl et al., 2013), and injected this compound i.c.v. at a dose of $0.03 \mu \mathrm{g} / 10 \mu \mathrm{l}$. Assuming homogeneous brain distribution and an average mouse brain weight of $0.5 \mathrm{~g}$, these i.c.v. dose of elacridar would result in molar brain concentration of $0.1 \mu \mathrm{M}$. The effect of elacridar on P-gp was without relevance for these experiments, because we previously reported that bumetanide is not a P-gp substrate (Töllner et al., 2015).

The phenothiazine derivative methylene blue (Fig. 1), an old antimalarial drug that is widely used as a stain in biology and medicine, recently has been reported to be a partial substrate of Pgp and MRP2 (Senarathna et al., 2016). To exclude that inclusion of this compound for verifying the i.c.v. injection site interfered with bumetanide efflux from the brain, we compared bumetanide levels in control experiments with artificial CSF with or without methylene blue. Assuming homogeneous brain distribution and an average mouse brain weight of $0.5 \mathrm{~g}$, the i.c.v. dose of methylene blue administered with artificial CSF would result in a molar brain concentration of $0.1 \mathrm{mM}$.

\subsection{Analysis of bumetanide and probenecid}

For analysis of bumetanide in brain, animals were decapitated and brain samples were immediately homogenized (about $50 \mathrm{mg}$ brain tissue in $1 \mathrm{ml}$ distilled water), centrifuged for $20 \mathrm{~min}$ at $15,000 \mathrm{rpm}$ at $4{ }^{\circ} \mathrm{C}$, and the supernatant was purified by solid phase extraction, using a Chromabond HR-X column (Macherey-Nagel; Düren; Germany). Bumetanide was extracted from the column by methanol, the extract was evaporated to dryness by nitrogen, the residue was dissolved in $100 \mu \mathrm{l}$ buffer, and $20 \mu \mathrm{l}$ were used for analysis by high performance liquid chromatography (HPLC) as recently described in detail (Brandt et al., 2010). For analysis of bumetanide in plasma, blood was sampled after decapitation, centrifuged and plasma samples were stored deep-frozen until HPLC analysis as described previously (Brandt et al., 2010; Töllner et al., 2014). As standard for HPLC analysis, we used a commercial solution $(0.5 \mathrm{mg} / \mathrm{ml})$ of the sodium salt of bumetanide (Burinex). The detection limit for bumetanide was about $50 \mathrm{ng} / \mathrm{ml}$ in plasma with a retention time of $9.0 \mathrm{~min}$ and $100 \mathrm{ng} / \mathrm{g}(=0.28 \mu \mathrm{M})$ in brain tissue with a retention time of $12.0 \mathrm{~min}$.

The concentration of probenecid in plasma and brain was determined by HPLC under comparable conditions, and with the same sample preparation like for analysis of bumetanide. Detection limit in plasma was about $300 \mathrm{ng} / \mathrm{ml}$ and retention time was $7.5 \mathrm{~min}$.

The analysis of compounds in the brain did not consider the blood volume in the brain, because preliminary experiments, in which brain bumetanide levels in mice with and without brain perfusion were compared, did not indicate any significant difference in these levels. For these experiments, mice were perfused via the aorta with $0.01 \mathrm{M}$ phosphate buffer under anesthesia with chloral hydrate $30 \mathrm{~min}$ after i.v. administration of $10 \mathrm{mg} / \mathrm{kg}$ bumetanide. Brain levels were compared to those of mice receiving the same treatment but killed without perfusion. Average brain levels of bumetanide were $0.15 \mu \mathrm{g} / \mathrm{g}$ without perfusion vs. $0.14 \mu \mathrm{g} / \mathrm{g}$ with perfusion, respectively, so that all experiments described in the Results section were performed without perfusion.

\subsection{In vitro transport experiments with bumetanide}

For studying the in vitro potencies of probenecid, PAH and several other compounds to inhibit Oat3-mediated transport of bumetanide, Chinese hamster ovary ( $\mathrm{CHO}$ ) cells expressing mouse Oat3 and respective mock-transfected cells were used. These cell lines, which were first described by VanWert and Sweet (2008), were generated by one of us (D.H.S.) and provided for the present experiments. Oat3-mediated transport of $\left[{ }^{3} \mathrm{H}\right]$ bumetanide 
(Hartmann Analytic, Braunschweig, Germany; specific activity: 555 $\mathrm{GBq} / \mathrm{mmol}$ ) was evaluated by an uptake assay as described by VanWert and Sweet (2008) and Hasannejad et al. (2004) with some modifications. Cells were seeded with a density of $0.4 \times 10^{6}$ cells/ well on 12-well plates (Greiner Bio-One, Frickenhausen, Germany), and cultured in DMEM without antibiotics. The uptake assay was performed in triplicate two days after seeding. Culture medium was replaced by serum-free Opti-MEM ${ }^{\mathbb{R}}$ medium $\left(\right.$ Gibco $^{\mathbb{R}} /$ Life Technologies Corporation) with or without respective inhibitor for $10 \mathrm{~min}$ pre-incubation, followed by $5 \mathrm{~min}$ incubation at $37{ }^{\circ} \mathrm{C}$ on orbital shaker at $55 \mathrm{rpm}$ with a final concentration of $100 \mathrm{nM}$ bumetanide, including $\left[{ }^{3} \mathrm{H}\right.$ ]bumetanide diluted with cold bumetanide to an activity concentration of $3.7 \mathrm{kBq} / \mathrm{ml}$ (with or without inhibitor). After the medium was removed on ice, the cells were washed with ice-cold phosphate-buffered saline, lysed in lysis buffer ( $25 \mathrm{mM}$ Tris, $\mathrm{pH} 8,50 \mathrm{mM} \mathrm{NaCl}, 0.5 \%(\mathrm{w} / \mathrm{v})$ sodium deoxycholate $0.5 \%(\mathrm{w} / \mathrm{v})$, Triton $\mathrm{X}-100)$ and the amount of $\left[{ }^{3} \mathrm{H}\right]$-accumulation in the cells was quantified with a $\beta$-scintillation-counter (Microbeta Trilux, Perkin Elmer). This was normalized to the amount of total cell protein, which was determined by BCA ${ }^{\mathrm{TM}}$ protein assay kit (Thermo Scientific, Rockford, USA).

The following compounds were tested as inhibitors of Oat3mediated transport of bumetanide (Fig. 1): probenecid (1 mM), PAH (0.1 and $5 \mathrm{mM})$, cimetidine $(1 \mathrm{mM})$, digoxin $(10 \mu \mathrm{M})$, BUM5 $(430 \mu \mathrm{M})$, a lipophilic prodrug of bumetanide (the N,N-dimethylaminoethylester; Töllner et al., 2014), and BUM13 (430 $\mu \mathrm{M})$, a bumetanide derivative (5-(anilinomethyl)-3-(butylamino)-2phenoxy-benzenesulfonamide) in which the carboxylic group was replaced by an anilinomethyl group (Lykke et al., 2015). The idea behind testing BUM5 was that we recently observed in mice that following administration of equimolar doses of bumetanide and BUM5, plasma levels of bumetanide are higher after BUM5, but the diuretic effect is significantly lower, indicating that BUM5 may inhibit the Oat3-mediated uptake of bumetanide in the kidney (Töllner et al., 2014). BUM13 was included to evaluate whether the carboxylic group of bumetanide is a prerequisite for its transport by Oat3. For both bumetanide derivatives, also concentration:effect experiments were performed, with concentrations ranging from 5 to $430 \mu \mathrm{M}$. These experiments were performed as described above, but with an incubation period prolonged to $20 \mathrm{~min}$ on 96 -well plates (white Isoplates for liquid scintillation counting, Perkin Elmer, Rodgau, Germany). Concentrations of compounds used were based on previous in vitro or in vivo studies (Sugiyama et al., 2001; VanWert and Sweet, 2008; VanWert et al., 2010; Töllner et al., 2014; Lykke et al., 2015). Digoxin was included as "negative control", because at the concentration used $(10 \mu \mathrm{M})$, it should not inhibit Oat3 (Sugiyama et al., 2001; VanWert et al., 2010).

In additional experiments, uptake of the Oat3 substrate fluorescein (Fig. 1) was used to determine inhibition of Oat3-mediated transport (Wolman et al., 2013). The uptake assays were performed as described above, with $10 \mu \mathrm{M}$ fluorescein instead of $\left[{ }^{3} \mathrm{H}\right]$ bumetanide. The fluorescein uptake was measured with the FLUOstar OPTIMA spectrofluorometer (BMG Labtech, Ortenberg, Germany). The effects of bumetanide, probenecid, BUM5, and BUM13 on fluorescein uptake were compared at various concentrations, and $\mathrm{IC}_{50}$ s were determined. A sigmoidal model with variable slope was used to analyze concentration:effect relationships by nonlinear regression.

\subsection{Statistics}

Statistical analyses were performed using GraphPad Prism 6.0 software (San Diego, CA, US). Either parametric or nonparametric tests were used for statistical evaluation, depending on data distribution. For comparison of two groups, either Student's t-test or the Mann-Whitney $U$ test was used. In case of more than two groups we used analysis of variance (ANOVA) with post hoc testing and correction for multiple comparisons. Depending on data distribution, either the ANOVA F-test, followed posthoc by Dunnett's multiple comparison test, or the Kruskal-Wallis test followed posthoc by Dunn's multiple comparisons test were used. All tests were two-sided; a $p \leq 0.05$ was considered significant. G*Power Data Analysis (Faul et al., 2007) was used to calculate the necessary sample size for a specified power of $80 \%$. For this calculation, effect size and variation of data were estimated from preliminary experiments with i.c.v. administration of probenecid. Pharmacokinetic analyses were performed by the software PK-Solutions (Summit Research Services, Montrose, CO, U.S.A.).

\section{Results}

\subsection{Pharmacokinetic experiments with probenecid in mice}

In a first experiment, we administered probenecid systemically at a dose $(50 \mathrm{mg} / \mathrm{kg})$ that has previously been used to evaluate whether bumetanide is subject to transport by Oat3 at the BBB (Donovan et al., 2015; Töllner et al., 2015). As shown in Fig. 2A, plasma concentrations of probenecid rapidly declined from 45 to $75 \mathrm{~min}$ after administration with an average half-life of $0.5 \mathrm{~h}$. Compared to the high plasma concentrations of probenecid (average maximal concentration $=54.9 \mu \mathrm{g} / \mathrm{ml}$ ), much lower drug levels were determined in the brain (Fig. 2A). The average maximal brain concentration was $3.04 \mu \mathrm{g} / \mathrm{g}$, which corresponds to $10.5 \mu \mathrm{M}$ and is far below the probenecid levels that have been reported to inhibit Oat3 in the rodent brain in vivo (Miyajima et al., 2011). The brain:plasma concentration ratio of probenecid was about 0.05 (Fig. 2A), indicating that only $5 \%$ of the plasma concentration reached the brain.

Next, we determined probenecid concentrations in brain and plasma following unilateral i.c.v. administration in mice (Fig. 2B). As expected, only very low plasma concentrations of probenecid were determined, which were in the range of $10-20 \%$ of brain concentrations. Brain levels after i.c.v. administration of probenecid were higher in the ipsilateral (right) than contralateral hemisphere and dose-dependently increased over the tested dose range (Fig. 2B). At the highest i.c.v. dose $(150 \mu \mathrm{g})$, average whole brain levels were $39 \mu \mathrm{g} / \mathrm{g}(=137 \mu \mathrm{M})$ in the ipsilateral and $18.6 \mu \mathrm{g} / \mathrm{g}(=65 \mu \mathrm{M})$ in the contralateral hemisphere when being determined 45 min after i.c.v. administration. In an additional experiment, we determined probenecid in plasma and brain $\sim 15$ min after i.c.v. injection of probenecid (not illustrated). Brain concentrations were $179 \pm 24.3 \mu \mathrm{g} /$ $\mathrm{kg}(=620 \mu \mathrm{M})$ in the ipsilateral and $87.4 \pm 6.07 \mu \mathrm{g} / \mathrm{kg}(=306 \mu \mathrm{M})$ in the contralateral hemisphere, respectively. The ipsilateral probenecid concentration $(0.62 \mathrm{mM})$ determined $\sim 15$ min after administration was somewhat lower than the calculated concentration (1.05 mM; see Methods), which is obviously due to the rapid elimination of probenecid in mice. Plasma levels 15 min after $150 \mu \mathrm{g}$ probenecid were $8.3 \pm 1.02 \mu \mathrm{g} / \mathrm{ml}$, corresponding to a plasma:brain ratio of 0.046 .

Systemic administration of probenecid (50 mg/kg i.p.) was tolerated without any obvious adverse effects, whereas the highest i.c.v. dose of probenecid (150 $\mu \mathrm{g})$ induced ptosis, hunched posture and ruffled fur, which was observed for about $40 \mathrm{~min}$ after administration. No adverse effects were observed after the lower i.c.v. doses.

\subsection{Effects of i.c.v. probenecid on bumetanide brain levels in mice}

When probenecid was i.c.v. injected at different doses $15 \mathrm{~min}$ before i.v. administration of bumetanide $(10 \mathrm{mg} / \mathrm{kg})$ and 


\section{A Probenecid i.p.}
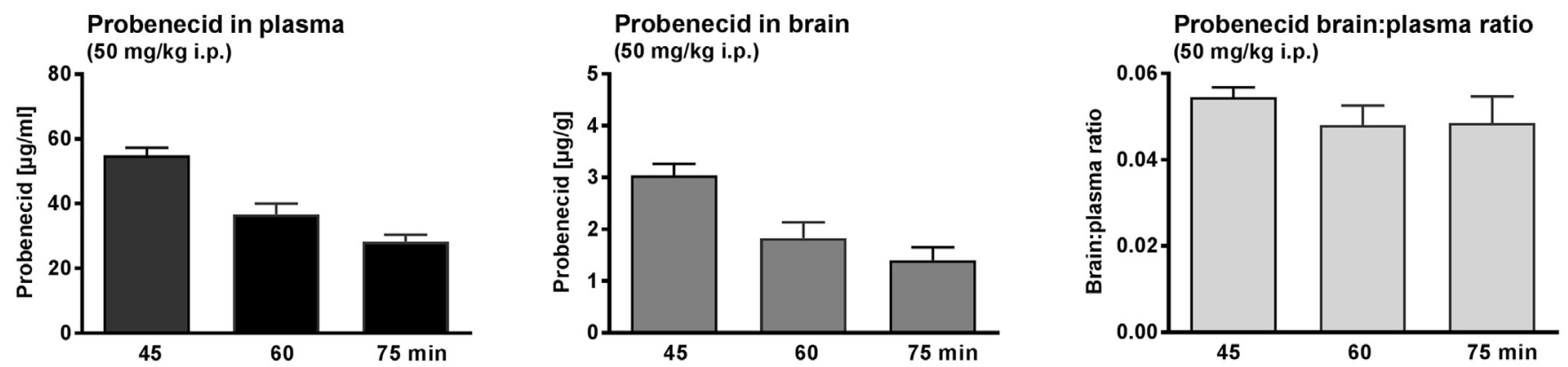

\section{B Probenecid i.c.v}
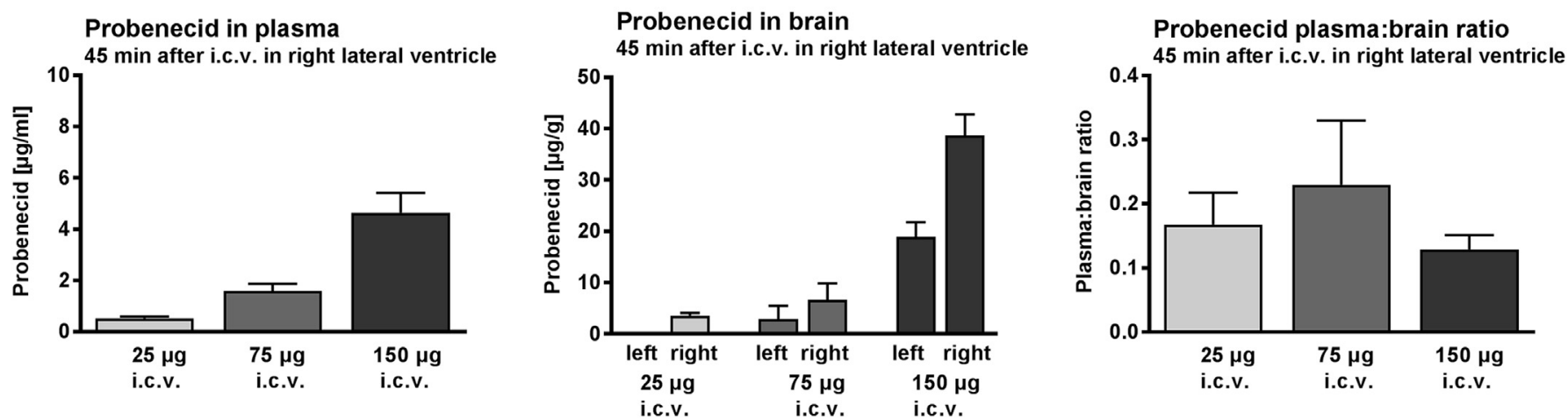

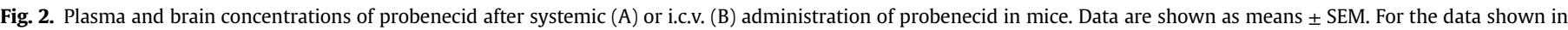

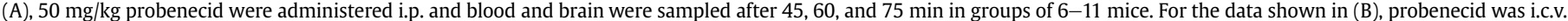

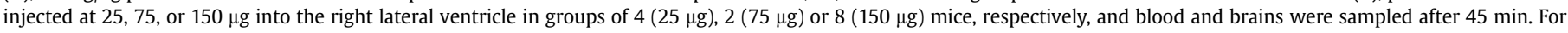

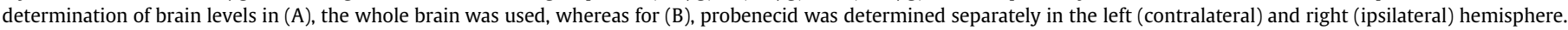

bumetanide levels in plasma and brain were determined $30 \mathrm{~min}$ later, a significant increase of bumetanide concentrations in the brain was only observed after the highest dose $(150 \mu \mathrm{g})$ of probenecid (Fig. 3A). The increase in bumetanide brain levels was the same in the left and right hemisphere, so that one may conclude that probenecid brain levels of at least $\sim 300 \mu \mathrm{M}$ were needed for inhibiting bumetanide efflux at the BBB, based on the probenecid brain levels determined in the pharmacokinetic experiments (see above). Bumetanide brain levels were in the range of $0.22-0.27 \mu \mathrm{g} /$ $\mathrm{g}(0.62-0.76 \mu \mathrm{M})$ and were doubled by $150 \mu \mathrm{g}$ probenecid i.c.v. As reported previously by us in mice (Töllner et al., 2014; Töpfer et al., 2014), the brain:plasma ratio of bumetanide was only about 0.01 and was significantly increased by $150 \mu \mathrm{g}$ probenecid (Fig. 3A). A moderate $(27 \%)$ but statistically significant increase of bumetanide plasma levels was only determined at the highest dose of probenecid. This small increase in plasma levels could not explain the $\sim 100 \%$ increase in brain levels of bumetanide, thus clearly indicating that probenecid inhibited active efflux of bumetanide from the brain.

In a subsequent experiment, $150 \mu \mathrm{g}$ probenecid were injected i.c.v. immediately (1-2 min) before i.v. administration of bumetanide $(10 \mathrm{mg} / \mathrm{kg})$, and brain and plasma levels of bumetanide were determined 15 min later (Fig. 3B). Brain levels of bumetanide were increased from $0.48 \mu \mathrm{g} / \mathrm{g}(1.35 \mu \mathrm{M})$ in vehicle controls to $\sim 1.4 \mu \mathrm{g} / \mathrm{g}$ $(\sim 3.9 \mu \mathrm{M})$ in probenecid-treated mice, i.e., an increase of $190 \%$. Plasma levels of bumetanide were not significantly altered. The brain:plasma ratio significantly increased from 0.01 to $\sim 0.03$, i.e., a significant increase of about $200 \%$. When probenecid was administered 30 min before bumetanide and mice were killed 15 min later, no significant effect of probenecid on brain levels of bumetanide was obtained (Fig. 3B), indicating that the timing of i.c.v. probenecid administration was critical for any effect on brain efflux of bumetanide.

\subsection{Effects of i.c.v. PAH on bumetanide brain levels in mice}

As shown in Fig. 4A, neither 50 nor $100 \mu \mathrm{g}$ PAH, injected i.c.v. into the right lateral ventricle of mice, significantly altered brain or plasma levels of bumetanide, when PAH was administered 1-2 min before bumetanide and mice were killed $15 \mathrm{~min}$ later. This prompted us to further increase the i.c.v. dose of PAH. At 250 and $500 \mu \mathrm{g}$ PAH, significant increases of bumetanide brain levels and bumetanide brain:plasma ratio were observed, but these increases were restricted to the contralateral (left) hemisphere. Furthermore, generalized convulsive seizures with running and bouncing and mortality were observed within a few minutes after injection. When the i.c.v. dose of PAH was further increased to $1000 \mu \mathrm{g}$, seizures became so severe that the experiment was terminated after 2 mice (data not shown).

To exclude that the increased bumetanide brain levels were due to seizure-induced BBB disruption, the experiment with $250 \mu \mathrm{g}$ $\mathrm{PAH}$ was repeated under anesthesia with isoflurane for the whole duration of the experiment, which blocked seizures and mortality. As shown in Fig. 4A, a significant increase in bumetanide 


\section{A Probenecid i.c.v., bumetanide i.v.}
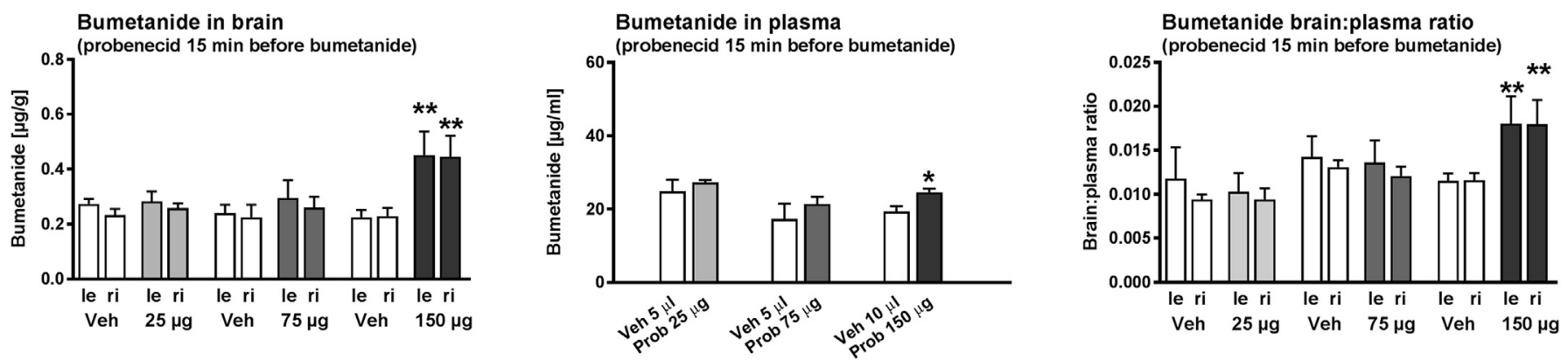

\section{B Probenecid i.c.v., bumetanide i.v.}
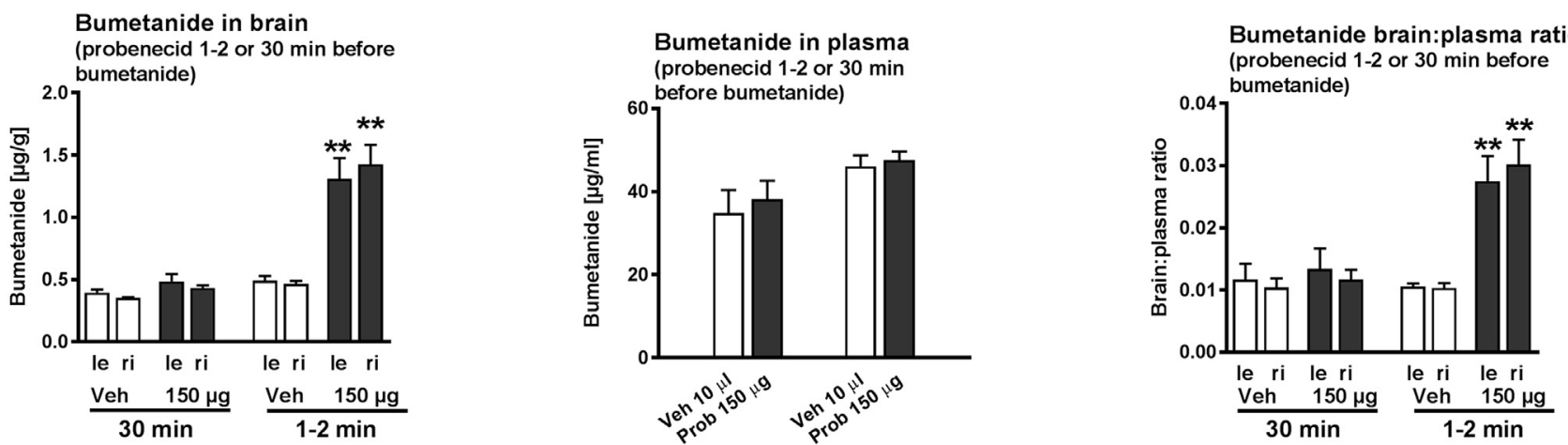

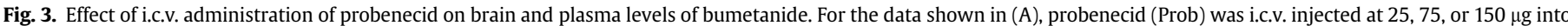

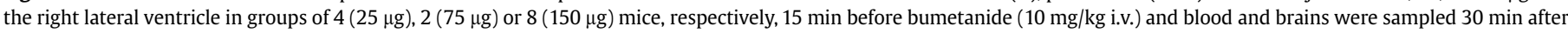

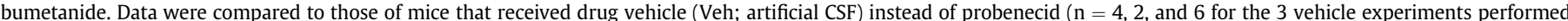

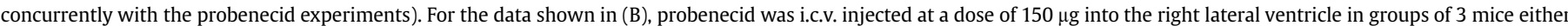

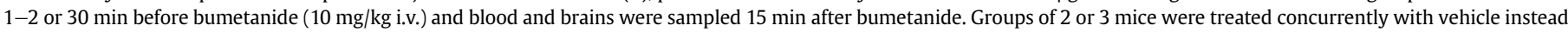

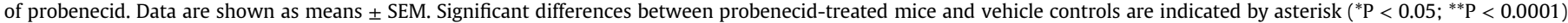

brain:plasma ratio of $\sim 40 \%$ above control was observed in both hemispheres.

\subsection{Effects of i.c.v. taurocholate on bumetanide brain levels in mice}

In a first experiment, taurocholate $(108 \mu \mathrm{g} / 10 \mu \mathrm{l})$ was injected i.c.v. without maintenance of anesthesia. Since running and bouncing was observed in part of the mice, the experiment was repeated under anesthesia. As shown in Fig. 4B, significant increases in bumetanide brain levels and brain:plasma ratio were observed in both experiments. The increase in brain:plasma ratio under anesthesia, which was significant in both hemispheres, was in the range of $30-50 \%$ above control.

\subsection{Effects of i.c.v. elacridar and methylene blue on bumetanide} brain levels in mice

The P-gp/Bcrp inhibitor elacridar did not affect bumetanide levels after i.c.v. injection in mice (Fig. 4B). Potential effects of methylene blue were evaluated by comparing vehicle control experiments with and without methylene blue. Ipsilateral brain:plasma ratios of bumetanide from such experiments were $0.012 \pm 0.0027$ (mean \pm S.D. of 39 mice) with methylene blue vs. $0.013 \pm 0.0046$ (mean \pm SEM of 13 mice) without methylene blue $(\mathrm{P}=0.1613)$, indicating that methylene blue did not affect bumetanide transport at the BBB under these conditions.

\subsection{In vitro transport experiments with bumetanide}

In $\mathrm{CHO}$ cells transfected with murine Oat3, transport of bumetanide was 4-7 times greater than nonspecific uptake in mock-transfected $\mathrm{CHO}$ cells (Fig. 5). If the data obtained with Oat3 inhibitors were background corrected to the mock levels, probenecid $(1 \mathrm{mM})$ almost completely inhibited the Oat3-mediated uptake of bumetanide, while digoxin $(10 \mu \mathrm{M})$ was ineffective as expected (Fig. 5A). PAH reduced bumetanide uptake by $24 \%$ at $100 \mu \mathrm{M}$ and $68 \%$ at $5 \mathrm{mM}$, respectively (Fig. 5A,C). Cimetidine ( $1 \mathrm{mM}$ ) reduced bumetanide uptake by $35 \%$. The bumetanide derivative BUM5 $(430 \mu \mathrm{M})$ inhibited bumetanide uptake completely and was therefore as effective as probenecid (Fig. 5C). The bumetanide derivative BUM13 $(430 \mu \mathrm{M})$ was slightly less effective than BUM5 in this regard, inhibiting bumetanide uptake by $\sim 88 \%$ (Fig. $5 \mathrm{C}$ )). When testing various concentrations of BUM5 and BUM13 on bumetanide uptake, an $\mathrm{IC}_{50}$ of $5 \mu \mathrm{M}$ was determined for BUM13, whereas BUM5 inhibited bumetanide almost completely at $5 \mu \mathrm{M}$ (not illustrated). None of these compounds significantly reduced the unspecific uptake of bumetanide in mock-transfected $\mathrm{CHO}$ cells.

When using fluorescein instead of bumetanide for uptake studies in CHO cells transfected with murine Oat3, probenecid $(1 \mathrm{mM})$ and BUM13 $(430 \mu \mathrm{M})$ inhibited the uptake of fluorescein by $86 \%$ and $91 \%$, respectively (not illustrated). When concentration:effect experiments were performed for determining $\mathrm{IC}_{50} \mathrm{~S}$, BUM13 ( IC $_{50} 18.32 \mu \mathrm{M}$ ) was about as potent to inhibit fluorescein 


\section{A. PAH i.c.v., bumetanide i.v.}
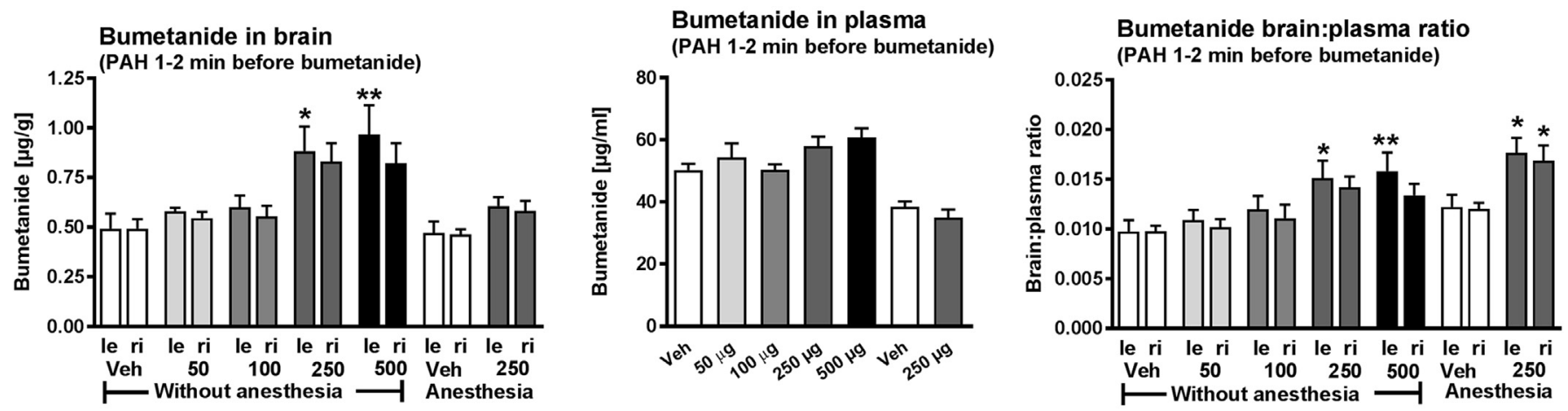

\section{B. Taurocholate or elacridar i.c.v., bumetanide i.v.}
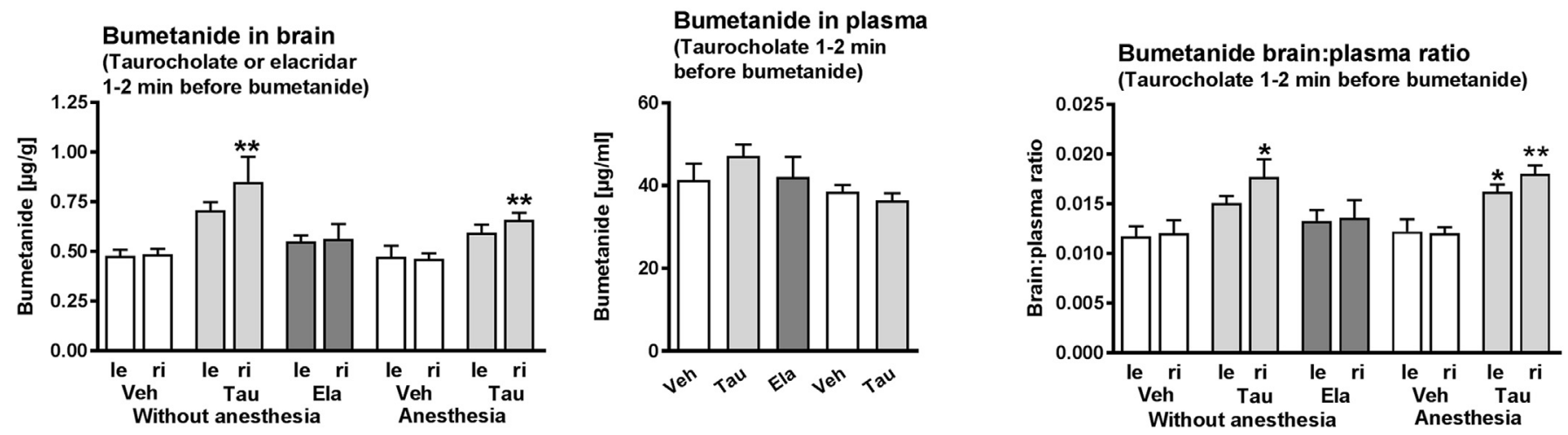

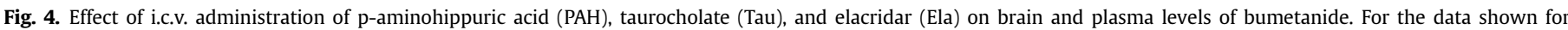

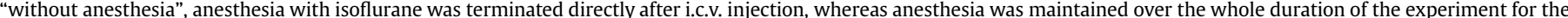

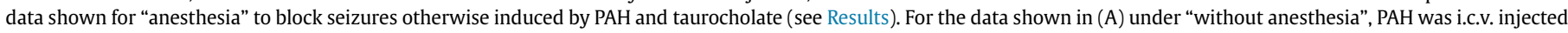

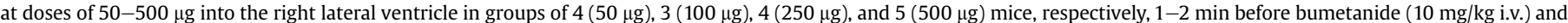

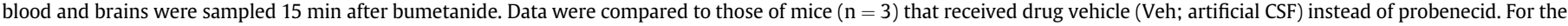

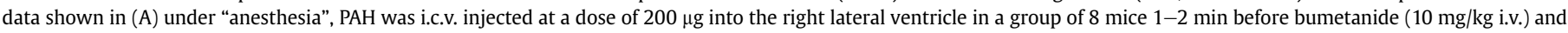

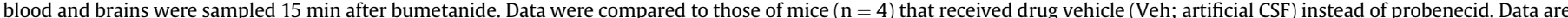

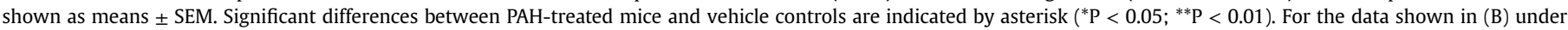

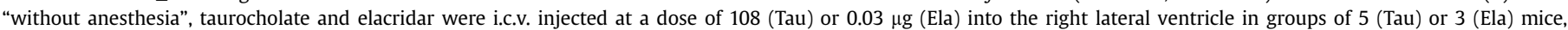

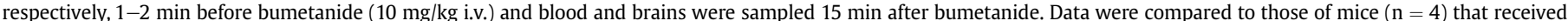

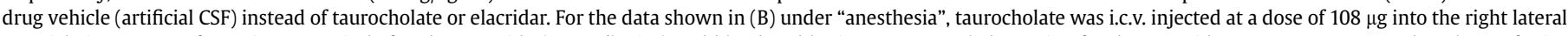

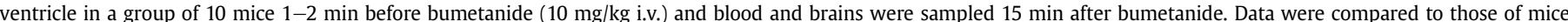

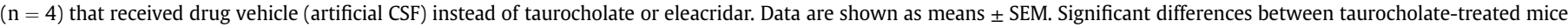
and vehicle controls are indicated by asterisk $\left({ }^{*} \mathrm{P}<0.05\right.$; $\left.{ }^{* *} \mathrm{P}<0.01\right)$.

uptake as bumetanide $(21.8 \mu \mathrm{M})$, but more potent than BUM5 $(75 \mu \mathrm{M})$.

\section{Discussion}

Donovan et al. $(2015,2016)$ recently proposed that bumetanide is subject to efflux transport by Oat 3 at the BBB. This proposal was based on (1) increase of bumetanide levels in brain dialysates collected from the hippocampus in rats, following intra-arterial administration of probenecid (50 $\mathrm{mg} / \mathrm{kg}$ ), and (2) bidirectional transport studies with bumetanide in human OAT3-transfected Madin-Darby canine kidney (MDCK) cells, in which basolateralto-apical bumetanide transport was inhibited by probenecid and benzylpenicillin. However, as also shown by our recent study with systemic administration of probenecid in mice (Töllner et al., 2015), the in vivo increase in brain bumetanide levels was most likely a consequence of increased plasma levels, due to inhibition of Oat3 in the kidney, and not a result of inhibition of BBB efflux. The present pharmacokinetic data on probenecid clearly substantiate the latter interpretation, because systemic administration of probenecid (50 $\mathrm{mg} / \mathrm{kg}$ ) did not lead to brain levels high enough to inhibit Oat3 or other efflux transporters at the BBB in vivo.

Indeed, after i.p. injection of probenecid in mice, a brain:plasma ratio of only about 0.05 was determined with maximum brain concentrations of only $\sim 10 \mu \mathrm{M}$. Previous experiments, in which unbound probenecid levels in plasma were compared with probenecid levels in the brain interstitial fluid, brain tissue and CSF in rats, found that the efflux clearance of probenecid from brain to plasma was 5-times greater than the influx clearance, indicating that active efflux at the BBB is involved in the low brain concentrations of probenecid (Deguchi et al., 1997). Probenecid (4(dipropylsulfamoyl)benzoic acid) is a relatively strong acid ( pka $=3.4$ ), with a high ionization rate at physiological $\mathrm{pH}$ and high protein binding (85-95\%) (Grosser et al., 2011), both of which limit 
A

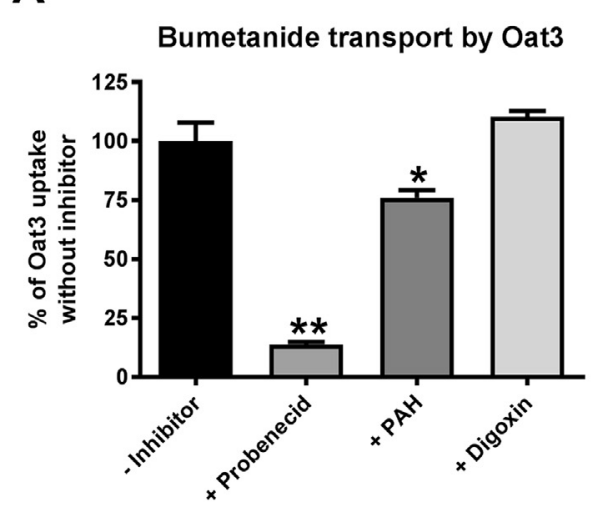

C

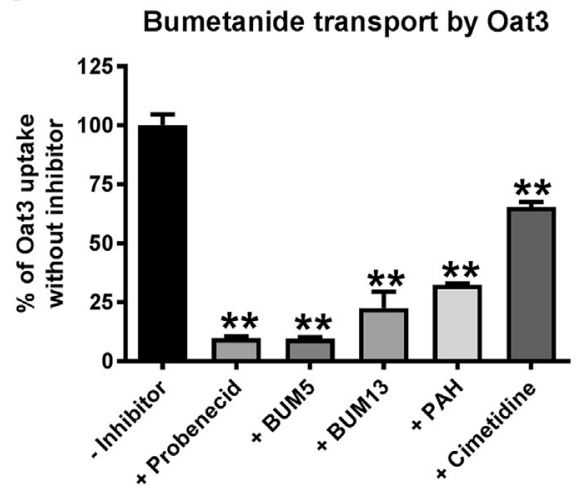

B
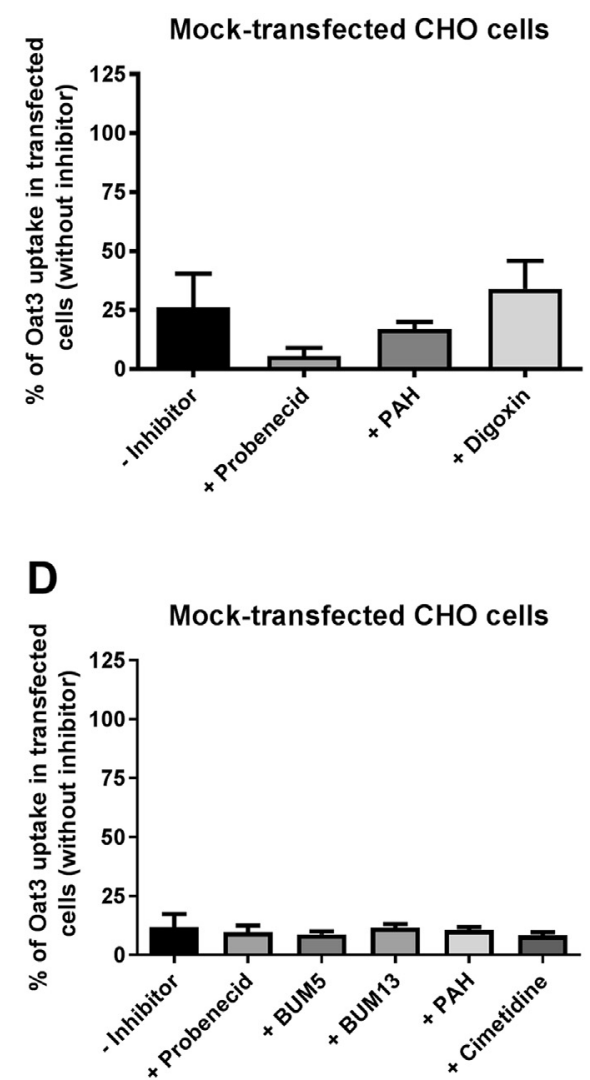

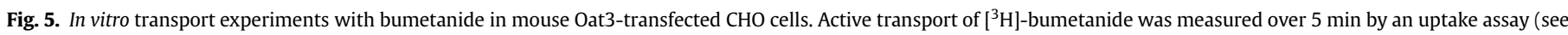

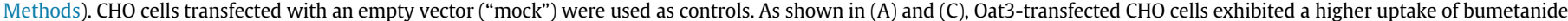

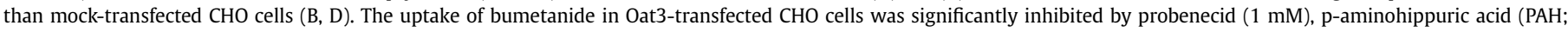

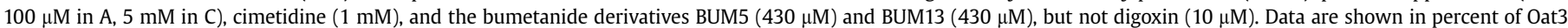

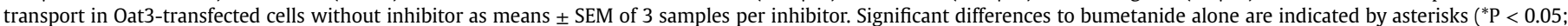
$\left.{ }^{* *} \mathrm{P}<0.0001\right)$.

its penetration into the brain by passive diffusion. Furthermore, active brain efflux of probenecid by MRPs, the monocarboxylic acid transport (MCT) system, Bcrp, PAH-sensitive organic anion transport systems (most likely including Oat3) of the solute carrier (SLC) superfamilies, and possibly other transporters at the BBB further reduces its brain levels (Deguchi et al., 1997; Roch-Ramel, 1998; Sugiyama et al., 2001; Merino et al., 2006; Vijay and Morris, 2014). Thus, at the high doses or concentrations commonly used, probenecid is not a selective inhibitor of Oat3, but inhibits other Oats, several Oatps, MRPs and MCTs that are expressed at the BBB (Sugiyama et al., 2001; Sun et al., 2003; VanWert et al., 2010; Vijay and Morris, 2014). As a consequence, based on the data reported by Donovan et al. $(2015,2016)$ with bumetanide and probenecid, it is not possible to conclude that the low brain levels of bumetanide, which we first reported in rats (Brandt et al., 2010), are a result of active efflux by Oat3 at the BBB.

This prompted us to use i.c.v. administration of probenecid and more selective Oat and Oatp inhibitors as a means to determine whether bumetanide is subject to active brain efflux in mice and which transporters are involved in this efflux. Intracerebral or i.c.v. administration of probenecid, $\mathrm{PAH}$ and other inhibitors of BBB transporters is widely used to study the uptake and efflux of drugs across the BBB in rodents (Laursen and Belknap, 1986; Kakee et al., 1996; Kusuhara and Sugiyama, 2004, 2005; Glascock et al., 2011). By direct injection of low doses of a transport inhibitor into the brain, inhibition of peripheral transporters in kidney and liver is minimized. Of the various members of the SLC transporter families, only Oat3 and Oatp1a4 (previously termed Oatp2) seem to be expressed at the rodent BBB at functionally relevant levels (Kamiie et al., 2008; Urquhart and Kim, 2009; Uchida et al., 2011). Oat3 is predominantly expressed at the abluminal (basolateral) membrane of BCECs and may eliminate its substrates out of the brain in concert with luminal (apical) efflux transporters such as Bcrp or Mrps (Fig. 6). However, lower expression of Oat3 has also been reported for the luminal membrane of rat BCECs (Kikuchi et al., 2003). Both Oat3 and Oatp1a4 are inhibited by probenecid (Sugiyama et al., 2001, Table 1). Bumetanide is long known to be transported by Oat3 (and other Oats) in the kidney (Burckhardt, 2012), but, to our knowledge, it is not established whether it is also a substrate of Oatp1a4. In Xenopus laevis oocytes expressing OAT3 or Oatp1a4, saturable uptake of bumetanide was reported for both transporters, but this study is as yet only available in abstract form (Goda et al., 2010). Interestingly, both probenecid and bumetanide have been shown to inhibit Oatp1a1 (previously termed Oatp1), another member of the Oatp family (Schwab et al., 2001). In addition, bumetanide is a substrate and inhibitor of MRP4 (Uchida et al., 2007; Hasegawa et al., 2007), which is expressed at the luminal membrane of BCECs, including the mouse BBB (Leggas et al., 2004; Kusuhara and Sugiyama, 2005; Kamiie et al., 2008), and acts as an efflux transporter, which is inhibited by probenecid (Van Aubel et al., 2002; Leggas et al., 2004). In an in vivo study that is as yet only available in abstract form, Goda et al. (2010) reported saturable 


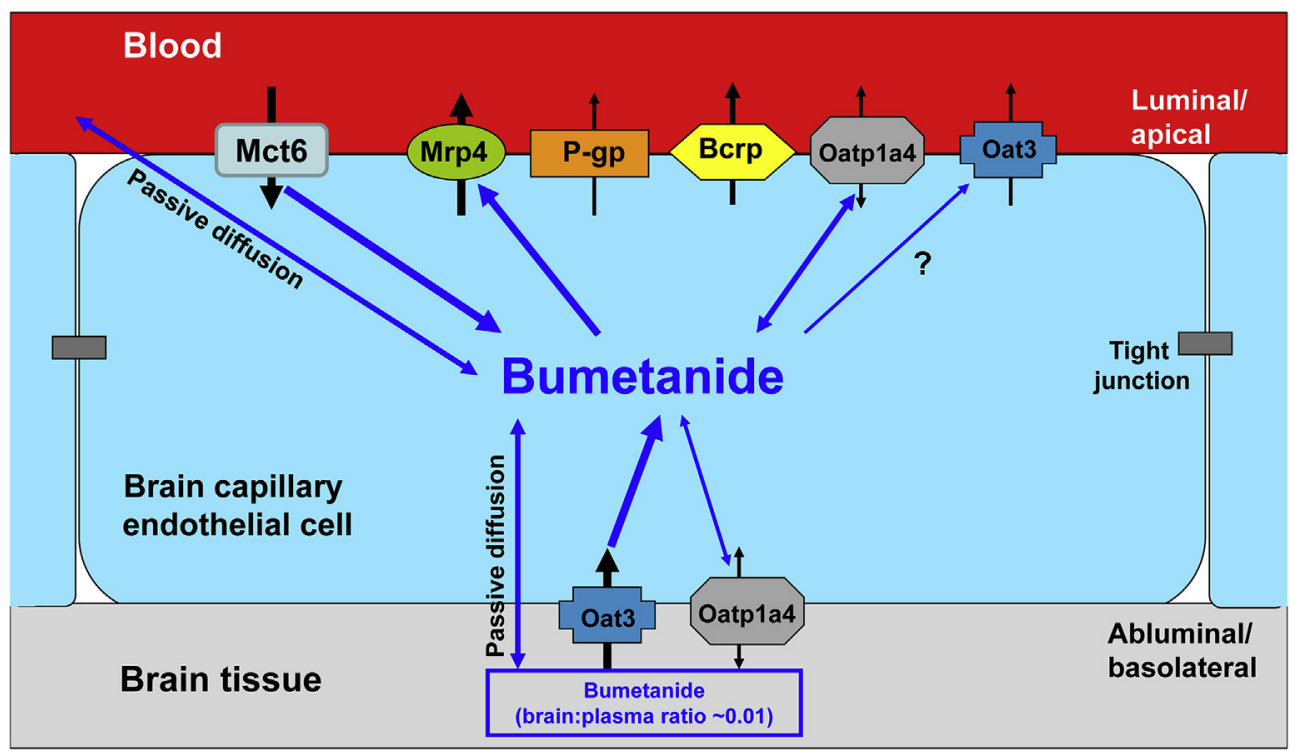

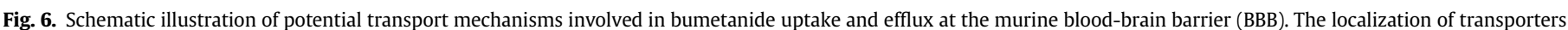

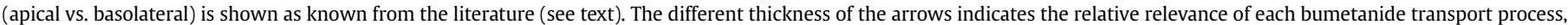

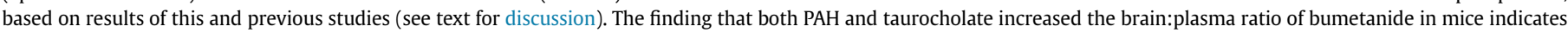

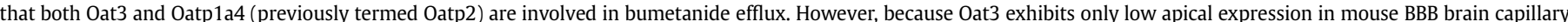

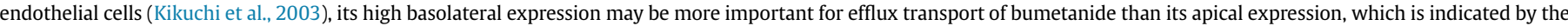

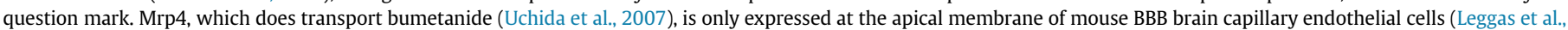

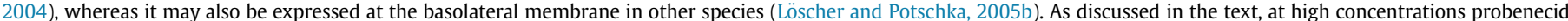

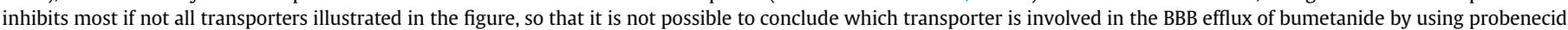
alone. However, as indicated by the present experiments with elacridar, P-gp and Bcrp seem not to be involved in bumetanide efflux.

bumetanide efflux from the rat brain that appeared to be mediated by a combination of Oat3 and Oatp1a4 as indicated by the effects of inhibitors of Oat3 (PAH, cimetidine) and Oatp1a4 (taurocholate and digoxin). In apparent contrast, the MRP4 inhibitor indomethacin was without effect on bumetanide efflux from the brain (Goda et al., 2010). However, most of the transport inhibitors used by Goda et al. (2010) are not specific. For instance, digoxin is also a substrate of Pgp (Wessler et al., 2013), which prompted us to study whether bumetanide is a substrate of this major efflux transporter (Töllner et al., 2015). No P-gp-mediated transport of bumetanide was observed in P-gp-overexpressing pig kidney LLC-PK1 cells, whereas a moderate but statistically significant transport was observed in LLC-PK1 cells overexpressing murine Bcrp (Töllner et al., 2015). In high concentrations, bumetanide was shown to inhibit BCRP (Hasegawa et al., 2007). Furthermore, bumetanide was shown to be transported by MCT6 (SLC16A5; Murakami et al., 2005), which is expressed in the brain as an uptake carrier (Morris and Felmlee, 2008), and can be inhibited by probenecid (Murakami et al., 2005). Thus, as illustrated in Fig. 6, the ABC transporters Bcrp and Mrp4 as well as the SLC transporters Oat3 and Oatp1a4 and Mct6 may be involved in active transport of bumetanide at the rodent BBB. All of them are expressed at the mouse BBB (Kamiie et al., 2008) and can be inhibited by probenecid (see above) at the high brain concentrations achieved in this study by i.c.v. administration.

As shown here, i.c.v. injection of probenecid in mice markedly ( $\sim 3$ fold) increased the brain:plasma ratio of bumetanide, clearly indicating active efflux of bumetanide at the BBB by probenecidsensitive efflux transporters. Probenecid brain levels of at least $\sim 300 \mu \mathrm{M}$ were needed for inhibiting bumetanide efflux at the BBB, which is more than an order of magnitude higher than the brain levels of probenecid achieved with systemic administration, further substantiating that the previously reported increase of bumetanide brain levels by systemic administration of probenecid (Donovan et al., 2015; Töllner et al., 2015) was not due to inhibition of BBB efflux. Since PAH is more selective for inhibiting OATs than probenecid (Sugiyama et al., 2001; Kusuhara and Sugiyama, 2005), it can be used to further specify active transport of drugs at the BBB (Sun et al., 2003). For instance, while probenecid inhibits both Oats and Oatps in transfected LLC-PK1 cells, PAH only inhibits Oats (Sugiyama et al., 2001). For Oat3, PAH was about 15-times less potent inhibitor than probenecid (Sugiyama et al., 2001), which is also shown by the data from different studies summarized in Table 1 . Our in vitro experiments with mouse Oat 3 in transfected $\mathrm{CHO}$ cells showed that PAH is $\sim 10$-times less potent than probenecid to inhibit transport of bumetanide by this SLC transporter. However, like probenecid, PAH is also a substrate and inhibitor of several MRPs, including Mrp4 (Leier et al., 2000; Van Aubel et al., 2000; Smeets et al., 2004), which, similar to SLC transporters, can transport a large range of organic anions, including bumetanide, and are expressed as efflux transporters at the BBB (Borst et al., 2000; Dallas et al., 2006).

In the present experiments, i.c.v. administration of PAH at doses of 50 and $100 \mu \mathrm{g}(\sim 0.5$ and $1 \mathrm{mM} / \mathrm{g}$ brain) in mice did not exert any significant effect on bumetanide brain concentrations. However, further increasing the dose to 250 and $500 \mu \mathrm{g}(\sim 2.5$ and $5 \mathrm{mM} / \mathrm{g}$ brain) resulted in significant increases in bumetanide brain:plasma ratio, although these increases were far below those observed with probenecid. The effective i.c.v. doses of PAH were in the range that has been reported previously to partially inhibit the brain efflux of the Oat3 substrate dehydroepiandrosterone sulfate after intracerebral PAH injection in mice (Miyajima et al., 2011). Our findings thus do not support the previous hypothesis of Donovan et al. $(2015,2016)$ that Oat3 is critically involved in bumetanide efflux at the $\mathrm{BBB}$, but the marked effect of probenecid must involve other transporters as well.

For further determining which BBB transporters are involved, 
we performed experiments with taurocholate and elacridar. As shown in Table 1, taurocholate is a potent inhibitor of Oatp1a4, which is not inhibited by PAH. Following i.c.v. administration, taurocholate significantly increased the brain:plasma ratio of bumetanide, although again to a much lower extent than probenecid. Elacridar was without significant effect on brain efflux of bumetanide, indicating that P-gp or Bcrp are not involved. Furthermore, methylene blue, which was recently reported to be a joint substrate for both P-gp and Bcrp (Senarathna et al., 2016), did not significantly increase the brain:plasma ratio of bumetanide.

Thus, based on these data from i.c.v. administration of 5 transport inhibitors in mice, we suggest that the marked increase of brain:plasma ratio of bumetanide in response to probenecid is a result of concerted inhibition of several transporters, including Oat3, Oatp1a4, and MRP4. Although probenecid may also inhibit active uptake of bumetanide by Mct6 (Murakami et al., 2005), this has as yet not been shown for the brain, and seems not to counteract the increase of the bumetanide brain:plasma ratio by probenecid. P-gp and Bcrp do not seem to play any role in bumetanide efflux at the BBB.

In addition to transporter-mediated active efflux at the BBB, the high ionization rate and plasma protein binding of bumetanide would further restrict its brain concentrations, so that brain levels sufficient to inhibit neuronal NKCC1 are not reached unless very high, potentially toxic doses of the drug are administered (Löscher et al., 2013; Puskarjov et al., 2014). In case of passive diffusion, only the free (unbound to proteins) unionized concentration is available to enter the CNS through the BBB. However, even if a drug is highly protein bound (90\% or higher) the free:bound equilibrium is continuously and rapidly re-established, so that high plasma binding alone does not restrict penetration of a drug into the brain along a concentration gradient. For instance, phenytoin and most benzodiazepines are highly bound to plasma proteins (>90\%), but both total and free concentrations in the brain equal those in the blood within $<1 \mathrm{~h}$ after administration (depending on drug lipophilicity), because these drugs freely penetrate through the BBB by passive diffusion to reach concentration equilibrium (Rambeck et al., 2006; Marchi et al., 2009; Löscher et al., 2011). With respect to the low brain concentrations of bumetanide determined in the present and previous reports, it should be considered that functionally relevant brain levels of this drug could even be lower because (1) the present analysis of bumetanide in the brain did not consider the blood volume in the brain (although our preliminary experiments did not indicate that this is a major bias; see Methods), and (2) a fraction of bumetanide may not reach its neuronal target (NKCC1) but is for instance adsorbed to tissue proteins or epithelial walls/cells in the BBB and brain parenchyma, and metabolized there. In this respect, an ex vivo assay based on NKCC1 inhibition in brain parenchyma would provide a more direct measure of bumetanide access to brain tissue and would dispel concerns that even the low concentrations reported might still have effects. However, we are not aware of such an assay. A further interesting aspect when estimating functionally relevant non-protein bound bumetanide levels in the brain are cerebrospinal fluid (CSF) concentrations, which are often used as a surrogate measure of CNS availability of drugs (Shen et al., 2004). The CSF:serum ratio of bumetanide has been determined in dogs after i.v. administration of $50 \mathrm{mg} / \mathrm{kg}$, resulting in values of $0.001-0.004$, indicating that only $0.1-0.4 \%$ of the serum concentration is present in the CSF (Javaheri et al., 1993). Similar low brain:plasma ratios of bumetanide as found in the present and previous studies in adult animals have been also reported for neonates (Cleary et al., 2013), and, importantly, BBB disruption by seizures do not increase brain bumetanide levels in rodents (Töllner et al., 2014), indicating that active efflux of bumetanide at the BBB is still functional and keeps bumetanide brain levels low.

In conclusion, as shown in Fig. 6, the uptake and efflux of bumetanide at the BBB is much more complex than previously thought. It seems that both restricted passive diffusion and active efflux transport explain the extremely low brain concentrations that are achieved after systemic administration of bumetanide, limiting the use of this drug for targeting abnormal expression of neuronal NKCC1 in brain diseases such as epilepsy. We have recently shown that this limitation can be overcome by administering lipophilic prodrugs of bumetanide, such as BUM5, which rapidly penetrate the $\mathrm{BBB}$ and are metabolized to bumetanide in the brain (Töllner et al., 2014). Interestingly, BUM5 is less diuretic than bumetanide (Töllner et al., 2014), which can be explained by the present in vitro finding that BUM5 inhibits Oat3-mediated transport of bumetanide in kidney cells, thus reducing the renal concentration of bumetanide that can stimulate diuresis via inhibition of NKCC2. The bumetanide derivative BUM13, which lacks the carboxylic group of bumetanide, did also inhibit Oat3, although it does not seem to inhibit NKCC2, the kidney target for the diuretic effect of bumetanide, and is much less diuretic than bumetanide (Lykke et al., 2015). Donovan et al. (2016) recently proposed that coadministration of an Oat3 inhibitor and bumetanide is a putative augmentation strategy for CNS delivery of bumetanide. However, this strategy is not feasible because, as shown by the present data, inhibition of Oat3 alone only moderately increases brain bumetanide levels, and this effect occurs only at high proconvulsant doses of an Oat3 inhibitor. Probenecid, which inhibits several transporters involved in bumetanide efflux at the BBB, may be more promising, because it increases brain levels of bumetanide after systemic administration (Donovan et al., 2015; Töllner et al., 2015). However this increase in brain bumetanide levels is a consequence of inhibition of peripheral bumetanide transport, resulting in highly elevated bumetanide plasma levels (Töllner et al., 2015). It is thus questionable whether probenecid is a clinically useful strategy for increasing brain bumetanide levels.

\section{Acknowledgements}

This study was supported by a grant (Lo 274/15-1) from the Deutsche Forschungsgemeinschaft. We thank Mario Gabriel and Prof. Gerda Brunhofer for help with the synthesis of BUM5 and BUM13 and Martina Gramer, Maria Hausknecht, and Serge Dubov for skillful technical assistance.

\section{References}

Abbott, N.J., Patabendige, A.A., Dolman, D.E., Yusof, S.R., Begley, D.J., 2010. Structure and function of the blood-brain barrier. Neurobiol. Dis. 37, 13-25.

Bankstahl, J.P., Bankstahl, M., Römermann, K., Wanek, T., Stanek, J., Windhorst, A.D. Fedrowitz, M., Erker, T., Müller, M., Löscher, W., Langer, O., Kuntner, C., 2013. Tariquidar and elacridar are dose-dependently transported by P-glycoprotein and Bcrp at the blood-brain barrier: a small-animal positron emission tomography and in vitro study. Drug Metab. Dispos, 41, 754-762.

Ben Ari, Y., Khalilov, I., Kahle, K.T., Cherubini, E., 2012. The GABA excitatory/inhibitory shift in brain maturation and neurological disorders. Neuroscientist 18 , 467-486.

Blaesse, P., Airaksinen, M.S., Rivera, C., Kaila, K., 2009. Cation-chloride cotransporters and neuronal function. Neuron 61, 820-838.

Borst, P., Evers, R., Kool, M., Wijnholds, J., 2000. A family of drug transporters: the multidrug resistance-associated proteins. J. Natl. Cancer Inst. 92, 1295-1302.

Brandt, C., Nozadze, M., Heuchert, N., Rattka, M., Löscher, W., 2010. Disease-modifying effects of phenobarbital and the NKCC1 inhibitor bumetanide in the pilocarpine model of temporal lobe epilepsy. J. Neurosci. 30, 8602-8612.

Burckhardt, G., 2012. Drug transport by Organic Anion Transporters (OATs). Pharmacol. Ther. 136, 106-130.

Cleary, R.T., Sun, H., Huynh, T., Manning, S.M., Li, Y., Rotenberg, A., Talos, D.M., Kahle, K.T., Jackson, M., Rakhade, S.N., Berry, G., Jensen, F.E., 2013. Bumetanide enhances phenobarbital efficacy in a rat model of hypoxic neonatal seizures. PLoS. One 8, e57148.

Dallas, S., Miller, D.S., Bendayan, R., 2006. Multidrug resistance-associated proteins: 
expression and function in the central nervous system. Pharmacol. Rev. 58, $140-161$.

Deguchi, Y., Nozawa, K., Yamada, S., Yokoyama, Y., Kimura, R., 1997. Quantitative evaluation of brain distribution and blood-brain barrier efflux transport of probenecid in rats by microdialysis: possible involvement of the monocarboxylic acid transport system. J. Pharmacol. Exp. Ther. 280, 551-560.

Donovan, M.D., O'Brien, F.E., Boylan, G.B., Cryan, J.F., Griffin, B.T., 2015. The effect of organic anion transporter 3 inhibitor probenecid on bumetanide levels in the brain: an integrated in vivo microdialysis study in the rat. J. Pharm. Pharmacol. 67, 501-510.

Donovan, M.D., Schellekens, H., Boylan, G.B., Cryan, J.F., Griffin, B.T., 2016. In vitro bidirectional permeability studies identify pharmacokinetic limitations of NKCC1 inhibitor bumetanide. Eur. J. Pharmacol. 770, 117-125.

Faul, F., Erdfelder, E., Lang, A.G., Buchner, A., 2007. G*Power 3: a flexible statistical power analysis program for the social, behavioral, and biomedical sciences. Behav. Res. Methods 39, 175-191.

Glascock, J.J., Osman, E.Y., Coady, T.H., Rose, F.F., Shababi, M., Lorson, C.L., 2011. Delivery of therapeutic agents through intracerebroventricular (ICV) and intravenous (IV) injection in mice. J. Vis. Exp. 56, 2968.

Goda, S., Thorsheim, H.R. Taskar, K.S., Thomas, A.J., Smith, Q.R., 2010. Restricted Brain Distribution of Bumetanide Is Mediated by Active Efflux Transporters (Rat Oatp \&OAT3) at the Blood-brain Barrier. Published Meeting Abstracts. Number SA7187. American Association of Pharmaceutical Scientists AAPS 2010 (Ref Type: Abstract).

Grosser, T., Smyth, E., Fitzgerald, G.A., 2011. Anti-inflammatory, antipyretic, and analgesic agents; pharmacotherapy of gout. In: Brunton, L.L., Chabner, B.A., Knollmann, B.C. (Eds.), Goodman \& Gilmans's the Pharmacological Basis of Therapeutics, twelfth ed. McGraw-Hill, New York, pp. 959-1004.

Hasannejad, H., Takeda, M., Taki, K., Shin, H.J., Babu, E., Jutabha, P., Khamdang, S. Aleboyeh, M., Onozato, M.L., Tojo, A., Enomoto, A., Anzai, N., Narikawa, S. Huang, X.L., Niwa, T., Endou, H., 2004. Interactions of human organic anion transporters with diuretics. J. Pharmacol. Exp. Ther. 308, 1021-1029.

Hasegawa, M., Kusuhara, H., Adachi, M., Schuetz, J.D., Takeuchi, K., Sugiyama, Y. 2007. Multidrug resistance-associated protein 4 is involved in the urinary excretion of hydrochlorothiazide and furosemide. J. Am. Soc. Nephrol. 18, $37-45$

Javaheri, S., Davis, C., Rogers, D.H., 1993. Ionic composition of cisternal CSF in acute respiratory acidosis: lack of effect of large dose bumetanide. J. Neurochem. 61, 1525-1529.

Kahle, K.T., Staley, K.J., Nahed, B.V., Gamba, G., Hebert, S.C., Lifton, R.P., Mount, D.B., 2008. Roles of the cation-chloride cotransporters in neurological disease. Nat. Clin. Pract. Neurol. 4, 490-503.

Kaila, K., Price, T.J., Payne, J.A., Puskarjov, M., Voipio, J., 2014. Cation-chloride cotransporters in neuronal development, plasticity and disease. Nat. Rev. Neurosci. 15, 637-654.

Kakee, A., Terasaki, T., Sugiyama, Y., 1996. Brain efflux index as a novel method of analyzing efflux transport at the blood-brain barrier. J. Pharmacol. Exp. Ther. 277, 1550-1559.

Kamiie, J., Ohtsuki, S., Iwase, R., Ohmine, K., Katsukura, Y., Yanai, K., Sekine, Y. Uchida, Y., Ito, S., Terasaki, T., 2008. Quantitative atlas of membrane transporter proteins: development and application of a highly sensitive simultaneous LC MS/MS method combined with novel in-silico peptide selection criteria. Pharm. Res. 25, 1469-1483.

Kikuchi, R., Kusuhara, H., Sugiyama, D., Sugiyama, Y., 2003. Contribution of organic anion transporter 3 (Slc22a8) to the elimination of p-aminohippuric acid and benzylpenicillin across the blood-brain barrier. J. Pharmacol. Exp. Ther. 306, $51-58$.

Kim, D.H., Jung, J.S., Song, D.K., Suh, H.W., Huh, S.O., Kim, Y.H., 1998. Intracerebroventricular injection-induced increase in plasma corticosterone levels in the mouse: a stress model. J. Pharmacol. Toxicol. Methods 39, 71-73.

Kusuhara, H., Sugiyama, Y., 2004. Efflux transport systems for organic anions and cations at the blood-CSF barrier. Adv. Drug Deliv. Rev. 56, 1741-1763.

Kusuhara, H., Sugiyama, Y., 2005. Active efflux across the blood-brain barrier: role of the solute carrier family. NeuroRx 2, 73-85.

Laursen, S.E., Belknap, J.K., 1986. Intracerebroventricular injections in mice. Some methodological refinements. J. Pharmacol. Methods 16, 355-357.

Leggas, M., Adachi, M., Scheffer, G.L., Sun, D., Wielinga, P., Du, G., Mercer, K.E., Zhuang, Y., Panetta, J.C., Johnston, B., Scheper, R.J., Stewart, C.F., Schuetz, J.D. 2004. Mrp4 confers resistance to topotecan and protects the brain from chemotherapy. Mol. Cell Biol. 24, 7612-7621.

Leier, I., Hummel-Eisenbeiss, J., Cui, Y., Keppler, D., 2000. ATP-dependent paraaminohippurate transport by apical multidrug resistance protein MRP2. Kidney Int. 57, 1636-1642.

Löscher, W., Potschka, H., 2005a. Role of drug efflux transporters in the brain for drug disposition and treatment of brain diseases. Prog. Neurobiol. 76, 22-76.

Löscher, W., Potschka, H., 2005b. Drug resistance in brain diseases and the role of drug efflux transporters. Nat. Rev. Neurosci. 6, 591-602.

Löscher, W., Luna-Tortos, C., Römermann, K., Fedrowitz, M., 2011. Do ATP-binding cassette transporters cause pharmacoresistance in epilepsy? Problems and approaches in determining which antiepileptic drugs are affected. Curr. Pharm. Des. 17, 2808-2828.

Löscher, W., Puskarjov, M., Kaila, K., 2013. Cation-chloride cotransporters NKCC1 and KCC2 as potential targets for novel antiepileptic and antiepileptogenic treatments. Neuropharmacology 69, 62-74.

Lykke, K., Töllner, K., Römermann, K., Feit, P.W., Erker, T., Macaulay, N., Löscher, W.
2015. Structure-activity relationships of bumetanide derivatives: correlation between diuretic activity in dogs and inhibition of human NKCC2 variant A. Brit. J. Pharmacol. 172, 4469-4480.

Marchi, N., Betto, G., Fazio, V., Fan, Q., Ghosh, C., Machado, A., Janigro, D., 2009. Blood-brain barrier damage and brain penetration of antiepileptic drugs: role of serum proteins and brain edema. Epilepsia 50, 664-677.

Matsson, P., Pedersen, J.M., Norinder, U., Bergstrom, C.A., Artursson, P., 2009. Identification of novel specific and general inhibitors of the three major human ATP-binding cassette transporters P-gp, BCRP and MRP2 among registered drugs. Pharm. Res. 26, 1816-1831.

Merino, G., Real, R., Molina, A.J., Pulido, M.M., Prieto, J.G., Alvarez, A.I., 2006. Interaction of probenecid with the Breast Cancer Resistance Protein Transporter (BCRP/ABCG2). Lett. Drug. Des. Discov, 3, 236-241.

Miyajima, M., Kusuhara, H., Fujishima, M., Adachi, Y., Sugiyama, Y., 2011. Organic anion transporter 3 mediates the efflux transport of an amphipathic organic anion, dehydroepiandrosterone sulfate, across the blood-brain barrier in mice. Drug Metab. Dispos. 39, 814-819.

Morris, M.E., Felmlee, M.A., 2008. Overview of the proton-coupled MCT (SLC16A) family of transporters: characterization, function and role in the transport of the drug of abuse gamma-hydroxybutyric acid. AAPS. J. 10, 311-321.

Murakami, Y., Kohyama, N., Kobayashi, Y., Ohbayashi, M., Ohtani, H., Sawada, Y., Yamamoto, T., 2005. Functional characterization of human monocarboxylate transporter 6 (SLC16A5). Drug Metab. Dispos. 33, 1845-1851.

Ohtsuki, S., 2004. New aspects of the blood-brain barrier transporters; its physiological roles in the central nervous system. Biol. Pharm. Bull. 27, 1489-1496.

Ose, A., Kusuhara, H., Endo, C., Tohyama, K., Miyajima, M., Kitamura, S., Sugiyama, Y., 2010. Functional characterization of mouse organic anion transporting peptide $1 \mathrm{a} 4$ in the uptake and efflux of drugs across the blood-brain barrier. Drug Metab. Dispos. 38, 168-176.

Pressler, R.M., Boylan, G.B., Marlow, N., Blennow, M., Chiron, C., Cross, J.H., De Vries, L.S., Hallberg, B., Hellstrom-Westas, L., Jullien, V., Livingstone, V. Mangum, B., Murphy, B., Murray, D., Pons, G., Rennie, J., Swarte, R., Toet, M.C., Vanhatalo, S., Zohar, S., 2015. Bumetanide for the treatment of seizures in newborn babies with hypoxic ischaemic encephalopathy (NEMO): an openlabel, dose finding, and feasibility phase 1/2 trial. Lancet Neurol. 14, 469-477.

Puskarjov, M., Kahle, K.T., Ruusuvuori, E., Kaila, K., 2014. Pharmacotherapeutic targeting of cation-chloride cotransporters in neonatal seizures. Epilepsia 55, $806-818$.

Rambeck, B., Jürgens, U.H., May, T.W., Pannek, H.W., Behne, F., Ebner, A., Gorji, A., Straub, H., Speckmann, E.J., Pohlmann-Eden, B., Löscher, W., 2006. Comparison of brain extracellular fluid, brain tissue, cerebrospinal fluid, and serum concentrations of antiepileptic drugs measured intraoperatively in patients with intractable epilepsy. Epilepsia 47, 681-694.

Roch-Ramel, F., 1998. Renal transport of organic anions. Curr. Opin. Nephrol. Hypertens. 7, 517-524.

Schwab, D., Herling, A.W., Hemmerle, H., Schubert, G., Hagenbuch, B., Burger, H.J., 2001. Hepatic uptake of synthetic chlorogenic acid derivatives by the organic anion transport proteins. J. Pharmacol. Exp. Ther. 296, 91-98.

Senarathna, S.M., Page-Sharp, M., Crowe, A., 2016. The interactions of P-Glycoprotein with antimalarial drugs, including substrate affinity, inhibition and regulation. PLoS. One 11, e0152677.

Shen, D.D., Artru, A.A., Adkison, K.K., 2004. Principles and applicability of CSF sampling for the assessment of CNS drug delivery and pharmacodynamics. Adv. Drug Deliv. Rev. 56, 1825-1857.

Smeets, P.H., Van Aubel, R.A., Wouterse, A.C., van den Heuvel, J., Russel, F.G., 2004. Contribution of multidrug resistance protein 2 (MRP2/ABCC2) to the renal excretion of p-aminohippurate (PAH) and identification of MRP4 (ABCC4) as a novel PAH transporter. J. Am. Soc. Nephrol. 15, 2828-2835.

Sugiyama, D., Kusuhara, H., Shitara, Y., Abe, T., Meier, P.J., Sekine, T., Endou, H., Suzuki, H., Sugiyama, Y., 2001. Characterization of the efflux transport of 17beta-estradiol-D-17beta-glucuronide from the brain across the blood-brain barrier. J. Pharmacol. Exp. Ther. 298, 316-322.

Sun, H., Dai, H., Shaik, N., Elmquist, W.F., 2003. Drug efflux transporters in the CNS. Adv. Drug Deliv. Rev. 55, 83-105.

Töllner, K., Brandt, C., Töpfer, M., Brunhofer, G., Erker, T., Gabriel, M., Feit, P.W., Lindfors, J., Kaila, K., Löscher, W., 2014. A novel prodrug-based strategy to increase effects of bumetanide in epilepsy. Ann. Neurol. 75, 550-562.

Töllner, K., Brandt, C., Römermann, K., Löscher, W., 2015. The organic anion transport inhibitor probenecid increases brain concentrations of the NKCC1 inhibitor bumetanide. Eur. J. Pharmacol. 746, 167-173.

Töpfer, M., Töllner, K., Brandt, C., Twele, F., Bröer, S., Löscher, W., 2014. Consequences of inhibition of bumetanide metabolism in rodents on brain penetration and effects of bumetanide in chronic models of epilepsy. Eur. J. Neurosci. 39, $673-687$.

Uchida, Y., Kamiie, J., Ohtsuki, S., Terasaki, T., 2007. Multichannel liquid chromatography-tandem mass spectrometry cocktail method for comprehensive substrate characterization of multidrug resistance-associated protein 4 transporter. Pharm. Res. 24, 2281-2296.

Uchida, Y., Ohtsuki, S., Katsukura, Y., Ikeda, C., Suzuki, T., Kamiie, J., Terasaki, T., 2011. Quantitative targeted absolute proteomics of human blood-brain barrier transporters and receptors. J. Neurochem. 117, 333-345.

Urquhart, B.L., Kim, R.B., 2009. Blood-brain barrier transporters and response to CNS-active drugs. Eur. J. Clin. Pharmacol. 65, 1063-1070.

Van Aubel, R.A., Peters, J.G., Masereeuw, R., Van Os, C.H., Russel, F.G., 2000. Multidrug resistance protein mrp2 mediates ATP-dependent transport of classic 
renal organic anion p-aminohippurate. Am. J. Physiol. Ren. Physiol. 279, F713-F717.

Van Aubel, R.A., Smeets, P.H., Peters, J.G., Bindels, R.J., Russel, F.G., 2002. The MRP4/ ABCC4 gene encodes a novel apical organic anion transporter in human kidney proximal tubules: putative efflux pump for urinary cAMP and cGMP. J. Am. Soc. Nephrol. 13, 595-603.

VanWert, A.L., Sweet, D.H., 2008. Impaired clearance of methotrexate in organic anion transporter 3 (Slc22a8) knockout mice: a gender specific impact of reduced folates. Pharm. Res. 25, 453-462.

VanWert, A.L., Gionfriddo, M.R., Sweet, D.H., 2010. Organic anion transporters: discovery, pharmacology, regulation and roles in pathophysiology. Biopharm. Drug Dispos. 31, 1-71.

Vijay, N., Morris, M.E., 2014. Role of monocarboxylate transporters in drug delivery to the brain. Curr. Pharm. Des. 20, 1487-1498.

Wessler, J.D., Grip, L.T., Mendell, J., Giugliano, R.P., 2013. The P-glycoprotein transport system and cardiovascular drugs. J. Am. Coll. Cardiol. 61, 2495-2502.

Wolman, A.T., Gionfriddo, M.R., Heindel, G.A., Mukhija, P., Witkowski, S. Bommareddy, A., VanWert, A.L., 2013. Organic anion transporter 3 interacts selectively with lipophilic beta-lactam antibiotics. Drug Metab. Dispos. 41, $791-800$. 